\title{
Physiological and biochemical characterization of Sesamum germplasms tolerant to $\mathrm{NaCl}$
}

\author{
Tapaswini Hota ${ }^{1}$, C. Pradhan ${ }^{2}$, G. R. Rout ${ }^{1 *}$ \\ ${ }^{1}$ Department of Agril. Biotechnology, College of Agriculture, OUAT, Bhubaneswar-3, India. \\ ${ }^{2}$ Post Graduate Department of Botany, Utkal University, Bhubaneswar-4, India.
}

\begin{tabular}{|c|c|}
\hline ARTICLE INFO & ABSTRACT \\
\hline $\begin{array}{l}\text { Article history: } \\
\text { Received on: } 30 / 03 / 2016 \\
\text { Revised on: } 14 / 05 / 2016 \\
\text { Accepted on: } 28 / 07 / 2016 \\
\text { Available online: } 23 / 10 / 2016\end{array}$ & $\begin{array}{l}\text { Sesamum indicum L. (family-Pedaliaceae) is an economically important oil seed crop grown in tropical and sub- } \\
\text { tropical countries. It is widely used in food, nutraceutical, pharmaceutical industries. Salinity is considered as the } \\
\text { most important abiotic stress limiting to crop production. In this context, the present study was to evaluate the } \\
\text { Sesamum genotypes for salinity tolerance. Germinated seedlings }(15 \text {-d-old) were used to screen the germplsm at } \\
\text { different concentrations }(0,25 \mathrm{mM}, 50 \mathrm{mM}, 75 \mathrm{mM}, 100 \mathrm{mM}) \text { of } \mathrm{NaCl} \text { and observation was taken after } 15^{\text {th }}, 30^{\text {th }}\end{array}$ \\
\hline $\begin{array}{l}\text { Key words: } \\
\text { Sesamum genotype, Protein, } \\
\text { Proline, Salinity stress, } \\
\text { Oxidative enzymes. }\end{array}$ & $\begin{array}{l}\text { and } 45^{1} \text { days of treatment. Ion content }\left(\mathrm{Na}, \mathrm{Cl}, \mathrm{Ca}, \mathrm{Mg}^{+} \text {and } \mathrm{K}^{+}\right) \text {were measured after } 15 \text { days of treatment. } \\
\text { Fresh and dry weight was less in salt sensitive genotypes than tolerant genotypes. During increase of salinity } \\
\text { concentration, all the genotypes had a negative impact on roots. The seedlings showed reduced growth and } \\
\text { displayed variation in ion uptake thus accumulating } \mathrm{Na}^{+} \text {and } \mathrm{Cl}^{-} \text {in the roots. At higher concentration of salt } \\
\text { treatment showed the more dry weight and displayed more effective ion regulation by manipulating low } \mathrm{Na}^{+} / \mathrm{K}^{+} \\
\text {and } \mathrm{Na}^{+} / \mathrm{Ca}^{++} \text {ratio. The tolerant genotypes exhibited the lowest shoot } \mathrm{Na}^{+} \text {content under salinity conditions. } \\
\text { Higher proline accumulation was observed at } 100 \mathrm{mM} \text { after } 15 \text { days of } \mathrm{NaCl} \text { treatments in 'KM-13' genotype. } \\
\text { After } 15 \text { days of treatment, the genotype 'ES } 2138-2 \text { ' showed maximum proline accumulation. The total } \\
\text { carbohydrates contents increased in all the ten genotypes in presence of NaCl. Highest carbohydrate content was } \\
\text { found in genotype 'SI-1926' grown in } 100 \mathrm{mM} \text { NaCl. Enzyme activities are variable in different genotypes with } \\
\text { different concentration of } \mathrm{NaCl} \text {. This study will help in Sesamum improvement programme. }\end{array}$ \\
\hline
\end{tabular}

\section{INTRODUCTION}

Sesame (Sesamum indicum L.) family Pedaliaceae, is one of the oldest high-value, multipurpose oil seed crop grown widely in tropical and subtropical areas $[1,2]$. The average yield of sesame on global scale is 5.1 quintals/ha while, current world production is estimated at about 4.04 million tons annually [3]. India placed second in the world after Myanmar with 18.20 lakh ha and 6.10 lakh tons production respectively. The average yield of sesame on global scale is $5.11 \mathrm{q} / \mathrm{ha}$, while in India, it is 3.30 $\mathrm{q} / \mathrm{ha}$ which is very low [3]. It is widely used against various diseases including cancer, cold, colic etc [4]. Sesame oil contains an unique compound known as lignans. Lignans comprises sesamin, sesamolin, and a small amount of sesamol [5]. Lignans

\footnotetext{
* Corresponding Author

Email: grrout @ rediffmail.com
}

are also phytoestorgens and their conversion to enterolactone is very important in preventing hormone-dependent cancers (like breast and prostate) and cardiovascular diseases. Soil salinity is one of the most important problems for irrigated agriculture, which drastically affect crop productivity throughout the world. It is mainly due to low precipitation and high transpiration causing disturbance in salt balance in the soil and also renders ground water brackish and affects plant growth adversely [6,7]. Nearly, 80 million hectares of arable lands of the world are estimated to be affected by salt [8]. Salinity effects are more noticeable in arid and semiarid regions, mainly due to the acceleration of salinity by a deficit of precipitation and high temperature coupled with a high evaporation demand [9].

Salt stress changes the morphological, physiological and biochemical responses of plants [10]. High salinity causes lower water potential and induces both hyper osmotic and ionic stress and results in alteration in plant metabolism including ionic imbalances, water potentials and specific ion toxicity [6]. 
About $15 \%$ of the total land area of the world has been degraded by soil erosion and physical and chemical degradation including soil salinization. High salt concentrations cause an imbalance in cellular ions, resulting in ion toxicity and osmotic stress, which leads to the generation of reactive oxygen species (ROS). These cytotoxic ROS's are highly reactive and when the ability of plant for scavenging is less than the ROS production, they can seriously disrupt normal metabolism through oxidative damages to the photosynthetic pigments, proteins, nucleic acids and lipids [11,12]. $\mathrm{NaCl}$ is the most abundant salt found in environments effected by salinity because of its ability to compete with various nutrients resulting in nutrient deficiency and specific toxicity. Many crops tolerate salinity to a threshold level and above which yield decreases as the salinity increases. Screening of genotypes is necessary to identify the salt tolerant germplasm for breeding programme to evolve the salt tolerant and high yielding crop varieties. In this context, the present study was carried out to screen the ten Sesamum genotypes under salinity stress with physiological and biochemical mechanism.

\section{MATERIALS AND METHODS}

\subsection{Plant material and treatments}

The genetically pure seed material of 33 Sesamum genotypes representing different geographical locations in India was collected from the germplasm centre of AICRP in Sesamum at Orissa University of Agriculture \& Technology, Bhubaneswar, India. Out of them, 10 genotypes (SI-2138-2, S-0140, Prachi, Kanaka, SI-1025, SI-205, KM-13, IS-607-1-84, SI-1926 and ENT78-301) were selected basing on their germination and growth rate under different concentration of $\mathrm{NaCl}(0,25 \mathrm{mM}, 50 \mathrm{mM}, 75 \mathrm{mM}$, $100 \mathrm{mM})$ treatments. Seeds were sown into the pots $(20 \mathrm{~cm} \times 30$ $\mathrm{cm}$ ) filled with $5 \mathrm{~kg}$ soil (soil and sand in the ratio $3: 1$ ), $\mathrm{pH}$ of soil ranges from 5.96 to 6.35 and temperature of soil is 89 to $91^{\circ} \mathrm{F}$ and grown under the green house. Soil electrical conductivity was measured of the amount of salts in soil (salinity of soil). It is an important indicator of soil health. It is commonly expressed in units of milliSiemens per meter $(\mathrm{mS} / \mathrm{m})$. The seedlings were watered regularly with half strength Hoagland solution [13]. Different concentrations of $\mathrm{NaCl}(0,25 \mathrm{mM}, 50 \mathrm{mM}, 75 \mathrm{mM}$ and $100 \mathrm{mM}$ ) was added into 15 -day-old plant in every 2 days intervals upto 45 days. The morphological observation was taken after $15^{\text {th }}$, $30^{\text {th }}$ and $45^{\text {th }}$ days after the treatment. Salt stress in change of proteins, antioxidant enzymes (POD, SOD, GPX), chlorophyll content, proline and polyphenol contents and total carbohydrates contents were analyzed. Ten seedlings from each treatment were sampled randomly at $15^{\text {th }}, 30^{\text {th }}$ and $45^{\text {th }}$ days after $\mathrm{NaCl}$ treatment. Data on root and shoot length and plant fresh and dry weight were determined. All the plant samples were dried at $65 \pm 2{ }^{\circ} \mathrm{C}$ for 2 days in hot air oven to a constant weight as dry weight was determined. The ion content analysis was made after 15 days of the growth. After drying, the shoots were grounded and analysed for $\mathrm{Cl}^{-}, \mathrm{Mg}^{+2}, \mathrm{Na}^{+}, \mathrm{K}^{++}, \mathrm{Ca}^{+}$and $\mathrm{Na}^{+} / \mathrm{K}^{+}$and $\mathrm{Na}^{+} / \mathrm{Ca}^{+}$. The content of $\mathrm{Cl}^{-}, \mathrm{Mg}^{+2}, \mathrm{Na}^{+}, \mathrm{K}^{++}, \mathrm{Ca}^{+}$and $\mathrm{Na}^{+} / \mathrm{K}^{+}$and $\mathrm{Na}^{+} / \mathrm{Ca}^{+}$(mg/g dry weight) of shoot was determined from $500 \mathrm{mg}$ digested sample (5 $\mathrm{ml}$ sulphuric acid $+5 \mathrm{ml}$ perchloric acid) using the Atomic Spectrophotometer (M/S Thermo Fischer, Germany). A stand curve was drawn based on a graded series of standards (ranged from 10 to $100 \mathrm{mg} / \mathrm{l}$ ) of $\mathrm{Cl}^{-}, \mathrm{Mg}^{+2}, \mathrm{Na}^{+}, \mathrm{K}^{++}, \mathrm{Ca}^{+}$and $\mathrm{Na}^{+} / \mathrm{K}^{+}$and $\mathrm{Na}^{+} / \mathrm{Ca}^{+}$.

\subsection{Determination of total carbohydrate}

Five hundred milligrams of fresh leaves were taken into a tube and hydrolyzed with $5 \mathrm{ml} 2.5 \mathrm{~N} \mathrm{HCl}$ for $3 \mathrm{hrs}$ by the hot water bath. Further, the test tubes were cooled at room temperature and the sample was neutralized by adding solid sodium carbonate till the effervescence ceases. The volume was made to $100 \mathrm{ml}$ and centrifuged at $5000 \mathrm{rpm}$ for $15 \mathrm{~min}$. The supernatant was collected and $0.1 \mathrm{ml}$ aliquots from each sample were taken for analysis. The volume was made up to $1 \mathrm{ml}$ in all test tubes by adding distilled water. Four milliliter of anthrone reagent was added to each tube and heated for $8 \mathrm{~min}$ in a boiling water bath. Then, it was cooled rapidly and optical density (OD) was taken at $630 \mathrm{~nm}$.

\subsection{Proline content}

To determine the proline level, $0.5 \mathrm{~g}$ of leaf samples from each treatment were homogenized in $3 \%(\mathrm{w} / \mathrm{v})$ sulphosalycylic acid and then filtered through filter paper [14]. Mixture was heated at $100^{\circ} \mathrm{C}$ for $1 \mathrm{~h}$ in a hot water bath after addition of ninhydrin and glacial acetic acid. Reaction was stopped by putting in ice bath. The mixture was extracted with toluene and the absorbance of fraction with toluene aspired from liquid phase was read at 520 $\mathrm{nm}$. Proline concentration was determined by using calibration curve and expressed as $\mu \mathrm{g}$ proline per gm fresh weight basis.

\subsection{Estimation of protein}

$1 \mathrm{gm}$ fresh leaves of Sesamum were homogenized in ice cold trichloroacetic acid (TCA) buffer and incubated overnight at $4^{\circ} \mathrm{C}$. Then, the sample was centrifuged at $8000 \mathrm{rpm}$ for $20 \mathrm{mins}$. Supernatant was discarded and pellet was washed with acetone to remove the pigments. The sample was again centrifuged at 10,000 rpm for 10 mins and washed with $80 \%$ alcohol to remove phenolic compounds. This was centrifuged at $5000 \mathrm{rpm}$ for $10 \mathrm{mins}$ and the pellet was suspended in known volume of extraction buffer and kept in boiling water bath for 2 mins. $100 \mu \mathrm{l}$ aliquot was taken and volume was made up to $1 \mathrm{ml}$. Five milliliter of Reagent-C $(50 \mathrm{ml}$ of $2 \%$ sodium carbonate dissolved in $0.1 \mathrm{~N} \mathrm{NaOH}+1 \mathrm{ml}$ of $0.5 \%$ copper sulphate dissolved in $1 \%$ sodium potassium tatarate) was added, mixed well and kept for 10 mins. Further, $0.5 \mathrm{ml}$ of FolinCiocalteau reagent was added, mixed well and incubated in the dark for $30 \mathrm{mins}$ at room temperature. After blue colour developed, the OD was taken at $660 \mathrm{~nm}$. The protein content was calculated against the standard graph.

\subsection{Enzyme assays}

$500 \mathrm{mg}$ leaf tissues were grinded by using a mortar and pestle with $5 \mathrm{ml}$ extraction buffer containing $50 \mathrm{mM}$ potassium 
phosphate buffer $\mathrm{pH} 7.6$ and $0.1 \mathrm{mM}$ Na-EDTA. The homogenate was centrifuged at $15,000 \mathrm{~g}$ for $15 \mathrm{~min}$ and the supernatant fraction was used to assay for the various enzymes. All steps in the preparation of enzyme extracts were performed at $4^{\circ} \mathrm{C}$. The superoxide dismutase (SOD) (EC 1.15.1.1) activity was determined by measuring its ability to inhibit the photochemical reduction of nitro blue tetrazolium chloride (NBT), as described by Giannopolitis and Ries [15]. The reaction solution consisted of 50 $\mu 1$ of the enzyme extract, $50 \mathrm{mM}$ phosphate buffer ( $\mathrm{pH} 7.8$ ), 0.1 $\mu \mathrm{M}$ EDTA, $13 \mathrm{mM}$ methionine, $75 \mu \mathrm{M}$ nitroblue tetrazolium and 2 $\mu \mathrm{M}$ riboflavin in a total volume of $1.5 \mathrm{ml}$. After adding riboflavin, the test tubes were shaken manually and placed under fluorescent lighting from two $20 \mathrm{~W}$ lamps. The reaction was allowed to proceed for $15 \mathrm{~min}$, after which the lights were switched off. Reduction in NBT was estimated by reading the absorbance of the reaction mixture at $560 \mathrm{~nm}$, and one unit of SOD activity (U) was defined as the amount of enzyme required to cause $50 \%$ inhibition of the NBT reduction and the results were expressed as Unit/ $\mathrm{mg}$.

Peroxidase (POD) (EC 1.11.1.7) activity was determined with guaiacol as reducing substrate in a reaction mixture

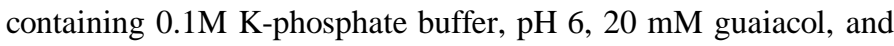
$30 \mathrm{mM} \mathrm{H} 2 \mathrm{O} 2$. The oxidation of guaiacol was assessed by recording the absorbance increase at $470 \mathrm{~nm}$ and $25{ }^{\circ} \mathrm{C}$ [16]. The enzyme unit was express as the absorbance change at $470 \mathrm{~nm}$, per minute, under the above conditions.

Glutathione peroxidase (PXR) was analysed by the method of Wendel [17]. $1 \mathrm{mg}$ of NADPH, $9.2 \mathrm{ml}$ of $1 \mathrm{mM}$ sodium azide solution (in $50 \mathrm{mM}$ sodium phosphate buffer with $0.4 \mathrm{mM}$ EDTA), $0.1 \mathrm{ml}$ of glutathione reductase enzyme solution $(100 \mathrm{U} / \mathrm{ml})$, and $0.05 \mathrm{ml}$ of glutathione reduced (GSH) were added and mixed by inversion.

Then, into $3 \mathrm{ml}$ of the mixture $0.05 \mathrm{ml}$ of enzyme extract was added. It was vortexes and incubated for $5 \mathrm{~min}$ at room temperature. After the incubation, $0.05 \mathrm{ml}$ of $\mathrm{H}_{2} \mathrm{O}_{2}$ was mixed immediately and measure at $340 \mathrm{~nm}$ after every $30 \mathrm{~s}$ over a period of $5 \mathrm{~min}$. GPX activity was calculated from the change in optical density per minute in the maximum linear rate range using a molar extinction coefficient for NADPH of $6.22 \times 103 / \mu \mathrm{mol}$ and assuming $2 \mathrm{~mol}$ of GSH formed for each mole of NADPH consumed. One unit activity was defined as $1 \mu \mathrm{mol}$ NADPH oxidized per minute.

\subsection{Statistical Analysis}

Each data point represents the mean of three samples \pm SE. Data were subjected to analysis of variance (ANOVA) followed by Duncan's multiple range test, and the significance level of $\mathrm{P}<0.05$ was employed

\section{RESULTS AND DISCUSSION}

Soil salinity is the major limiting factor for crop yield and productivity. Intensive agronomic practices, poor water management, irrigation without sufficient drainage systems, long periods of hot and dry seasons and high levels of evaporation lead to the stalinization of millions of hectares of agricultural land [5]. The present study showed that there was distinct growth effect of Sesamum genotypes in various concentrations of $\mathrm{NaCl}$. The growth attributes were decreased with increase of $\mathrm{NaCl}$ concentration. The results showed the both shoot and root fresh weight decreased in all genotypes but more prominent in one genotype SI-1926 (Table. 1).

Table 1: Fresh and dry weight of ten genotypes of Sesamum indicum L. grown in soil with application of different concentrations of $\mathrm{NaCl}$ after 15 days of treatment $(* 20$ replicates/treatment; repeated twice).

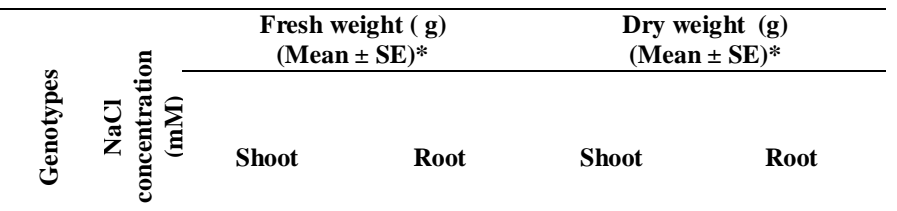

\begin{tabular}{|c|c|c|c|c|c|}
\hline \multirow{5}{*}{ 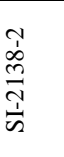 } & 0 & $22.5 \pm 1.7 \mathrm{~m}$ & $1.32 \pm 0.03 \mathrm{j}$ & $4.12 \pm 0.9 \mathrm{~h}$ & $0.23 \pm 0.01 \mathrm{f}$ \\
\hline & 25 & $7.64 \pm 1.2 \mathrm{e}$ & $0.72 \pm 0.05 \mathrm{~g}$ & $0.34 \pm 1.1 \mathrm{a}$ & $0.08 \pm 0.06 \mathrm{~b}$ \\
\hline & 50 & $6.09 \pm 1.1 \mathrm{~d}$ & $0.39 \pm 0.07 \mathrm{~d}$ & $2.08 \pm 0.9 \mathrm{f}$ & $0.09 \pm 0.04 \mathrm{~b}$ \\
\hline & 75 & $3.72 \pm 1.6 \mathrm{~b}$ & $0.29 \pm 0.09 \mathrm{c}$ & $0.55 \pm 0.2 \mathrm{~b}$ & $0.08 \pm 0.03 \mathrm{~b}$ \\
\hline & 100 & $2.60 \pm 1.2 \mathrm{a}$ & $0.26 \pm 0.07 \mathrm{c}$ & $0.35 \pm 0.5 \mathrm{a}$ & $0.04 \pm 0.07 \mathrm{a}$ \\
\hline \multirow{5}{*}{$\begin{array}{l}\text { O } \\
\\
1 \\
\text { n' }\end{array}$} & 0 & $23.4 \pm 1.5 \mathrm{n}$ & $1.51 \pm 0.031$ & $4.25 \pm 1.1 \mathrm{~h}$ & $0.29 \pm 0.05 \mathrm{~h}$ \\
\hline & 25 & $14.6 \pm 1.2 \mathrm{i}$ & $0.83 \pm 0.07 \mathrm{~h}$ & $3.31 \pm 0.9 \mathrm{~g}$ & $0.18 \pm 0.02 \mathrm{e}$ \\
\hline & 50 & $12.3 \pm 1.6 \mathrm{~h}$ & $0.76 \pm 0.05 \mathrm{~g}$ & $0.68 \pm 0.9 \mathrm{c}$ & $0.09 \pm 0.09 \mathrm{~b}$ \\
\hline & 75 & $10.6 \pm 2.5 \mathrm{~g}$ & $0.52 \pm 0.07 \mathrm{e}$ & $0.54 \pm 0.2 \mathrm{~b}$ & $0.08 \pm 0.07 \mathrm{~b}$ \\
\hline & 100 & $9.50 \pm 1.8 \mathrm{f}$ & $0.46 \pm 0.09 \mathrm{~d}$ & $0.41 \pm 0.8 \mathrm{a}$ & $0.07 \pm 0.04 \mathrm{~b}$ \\
\hline \multirow{5}{*}{ 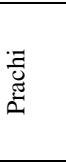 } & 0 & $20.3 \pm 1.21$ & $1.55 \pm 0.031$ & $4.00 \pm 0.6 \mathrm{~h}$ & $0.30 \pm 0.06 \mathrm{a}$ \\
\hline & 25 & $8.00 \pm 2.3 \mathrm{e}$ & $0.37 \pm 0.07 \mathrm{~d}$ & $3.43 \pm 0.4 \mathrm{~g}$ & $0.20 \pm 0.09 \mathrm{a}$ \\
\hline & 50 & $18.9 \pm 1.8 \mathrm{k}$ & $0.95 \pm 0.02 \mathrm{i}$ & $3.02 \pm 0.8 \mathrm{~g}$ & $0.22 \pm 0.07 \mathrm{a}$ \\
\hline & 75 & $13.9 \pm 1.1 \mathrm{i}$ & $0.60 \pm 0.04 \mathrm{f}$ & $1.38 \pm 0.5 \mathrm{e}$ & $0.09 \pm 0.06 \mathrm{~b}$ \\
\hline & 100 & $5.43 \pm 1.2 \mathrm{c}$ & $0.18 \pm 0.04 \mathrm{a}$ & $0.62 \pm 0.2 \mathrm{c}$ & $0.03 \pm 0.02 \mathrm{a}$ \\
\hline \multirow{5}{*}{ 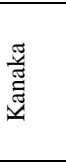 } & 0 & $25.0 \pm 1.5 \mathrm{o}$ & $1.94 \pm 0.02 \mathrm{~m}$ & $3.88 \pm 0.9 \mathrm{~h}$ & $0.31 \pm 0.03 \mathrm{~h}$ \\
\hline & 25 & $22.4 \pm 1.1 \mathrm{~m}$ & $1.58 \pm 0.031$ & $2.63 \pm 0.2 \mathrm{f}$ & $0.26 \pm 0.06 \mathrm{~g}$ \\
\hline & 50 & $20.8 \pm 1.01$ & $1.41 \pm 0.04 \mathrm{k}$ & $2.52 \pm 0.5 \mathrm{f}$ & $0.22 \pm 0.07 \mathrm{f}$ \\
\hline & 75 & $12.4 \pm 1.6 \mathrm{~h}$ & $0.75 \pm 0.07 \mathrm{~g}$ & $1.49 \pm 0.4 \mathrm{e}$ & $0.12 \pm 0.09 \mathrm{c}$ \\
\hline & 100 & $12.2 \pm 1.5 \mathrm{~h}$ & $0.86 \pm 0.05 \mathrm{~h}$ & $1.23 \pm 0.8 \mathrm{e}$ & $0.20 \pm 0.87 \mathrm{e}, \mathrm{f}$ \\
\hline \multirow{5}{*}{$\frac{2}{\frac{1}{2}}$} & 0 & $16.8 \pm 1.0 \mathrm{j}$ & $1.06 \pm 0.02 \mathrm{i}$ & $1.72 \pm 0.2 \mathrm{f}$ & $0.13 \pm 0.03 \mathrm{c}$ \\
\hline & 25 & $11.3 \pm 1.7 \mathrm{~g}$ & $0.62 \pm 0.07 \mathrm{f}$ & $1.29 \pm 0.7 \mathrm{e}$ & $0.12 \pm 0.09 \mathrm{c}$ \\
\hline & 50 & $7.37 \pm 1.1 \mathrm{e}$ & $0.43 \pm 0.04 \mathrm{~d}$ & $0.64 \pm 0.4 \mathrm{c}$ & $0.09 \pm 0.03 \mathrm{~b}$ \\
\hline & 75 & $6.48 \pm 1.7 \mathrm{~d}$ & $0.50 \pm 0.05 \mathrm{e}$ & $0.57 \pm 0.8 \mathrm{~b}$ & $0.08 \pm 0.04 \mathrm{~b}$ \\
\hline & 100 & $6.10 \pm 1.0 \mathrm{~d}$ & $0.53 \pm 0.04 \mathrm{e}$ & $0.91 \pm 0.2 \mathrm{~d}$ & $0.07 \pm 0.06 \mathrm{~b}$ \\
\hline \multirow{5}{*}{$\begin{array}{l}\stackrel{n}{d} \\
\frac{1}{n}\end{array}$} & 0 & $14.2 \pm 1.6 \mathrm{i}$ & $0.74 \pm 0.05 \mathrm{~g}$ & $1.54 \pm 0.9 \mathrm{f}$ & $0.10 \pm 0.02 \mathrm{~b}, \mathrm{c}$ \\
\hline & 25 & $10.4 \pm 2.2 \mathrm{~g}$ & $0.39 \pm 0.07 \mathrm{~d}$ & $0.92 \pm 0.9 \mathrm{~d}$ & $0.11 \pm 0.01 \mathrm{c}$ \\
\hline & 50 & $5.87 \pm 1.0 \mathrm{c}$ & $0.30 \pm 0.09 \mathrm{c}$ & $0.98 \pm 0.5 \mathrm{~d}$ & $0.12 \pm 0.04 \mathrm{c}$ \\
\hline & 75 & $7.61 \pm 1.1 \mathrm{e}$ & $0.28 \pm 0.05 \mathrm{c}$ & $0.56 \pm 0.2 \mathrm{~b}$ & $0.05 \pm 0.03 \mathrm{a}$ \\
\hline & 100 & $8.18 \pm 1.2 \mathrm{e}$ & $0.60 \pm 0.04 \mathrm{f}$ & $0.31 \pm 0.9 \mathrm{a}$ & $0.07 \pm 0.07 \mathrm{~b}$ \\
\hline \multirow{5}{*}{$\sum_{i}^{m}$} & 0 & $15.3 \pm 1.1 \mathrm{i}, \mathrm{j}$ & $0.88 \pm 0.07 \mathrm{~h}$ & $1.77 \pm 0.8 \mathrm{f}$ & $0.21 \pm 0.05 \mathrm{f}$ \\
\hline & 25 & $15.0 \pm 1.2 \mathrm{i}, \mathrm{j}$ & $0.77 \pm 0.05 \mathrm{~g}$ & $1.25 \pm 1.1 \mathrm{e}$ & $0.12 \pm 0.09 \mathrm{c}$ \\
\hline & 50 & $14.6 \pm 1.3 \mathrm{i}$ & $0.45 \pm 0.09 \mathrm{~d}$ & $0.59 \pm 0.8 \mathrm{c}$ & $0.09 \pm 0.07 \mathrm{~b}$ \\
\hline & 75 & $7.98 \pm 2.5 \mathrm{e}$ & $0.37 \pm 0.07 \mathrm{~d}$ & $1.03 \pm 0.1 \mathrm{~d}$ & $0.05 \pm 0.06 \mathrm{a}$ \\
\hline & 100 & $3.13 \pm 1.3 \mathrm{~b}$ & $0.31 \pm 0.16 \mathrm{c}$ & $0.97 \pm 0.5 \mathrm{~d}$ & $0.10 \pm 0.09 \mathrm{~b}, \mathrm{c}$ \\
\hline \multirow{5}{*}{$\begin{array}{l}\frac{1}{1} \\
\frac{1}{8} \\
0 \\
1 \\
\varrho \\
\varrho\end{array}$} & 0 & $11.2 \pm 1.2 \mathrm{~g}$ & $0.73 \pm 0.03 \mathrm{~g}$ & $1.37 \pm 0.8 \mathrm{e}$ & $0.12 \pm 0.07 \mathrm{c}$ \\
\hline & 25 & $7.90 \pm 1.0 \mathrm{e}$ & $0.18 \pm 0.09 \mathrm{a}$ & $0.52 \pm 0.4 \mathrm{~b}$ & $0.12 \pm 0.02 \mathrm{c}$ \\
\hline & 50 & $6.83 \pm 1.2 \mathrm{~d}$ & $0.13 \pm 0.07 \mathrm{a}$ & $0.62 \pm 0.8 \mathrm{c}$ & $0.13 \pm 0.07 \mathrm{c}$ \\
\hline & 75 & $9.94 \pm 1.1 \mathrm{~g}$ & $0.65 \pm 0.02 \mathrm{f}$ & $1.26 \pm 0.2 \mathrm{e}$ & $0.11 \pm 0.09 \mathrm{c}$ \\
\hline & 100 & $6.80 \pm 2.2 \mathrm{~d}$ & $0.13 \pm 0.05 \mathrm{f}$ & $0.83 \pm 0.4 \mathrm{~d}$ & $0.03 \pm 0.50 \mathrm{a}$ \\
\hline \multirow{5}{*}{$\frac{\stackrel{\Xi}{\sigma}}{\frac{1}{\sigma}}$} & 0 & $17.9 \pm 1.1 \mathrm{k}$ & $1.29 \pm 0.01 \mathrm{j}$ & $0.59 \pm 0.8 \mathrm{c}$ & $0.28 \pm 0.12 \mathrm{~h}$ \\
\hline & 25 & $16.7 \pm 1.3 \mathrm{j}$ & $0.85 \pm 0.04 \mathrm{~h}$ & $0.54 \pm 0.5 \mathrm{~b}$ & $0.20 \pm 0.87 \mathrm{e}, \mathrm{f}$ \\
\hline & 50 & $15.3 \pm 1.2 \mathrm{i}, \mathrm{j}$ & $0.75 \pm 0.03 \mathrm{~g}$ & $0.38 \pm 0.2 \mathrm{a}$ & $0.12 \pm 0.05 \mathrm{c}$ \\
\hline & 75 & $7.09 \pm 0.9 \mathrm{e}$ & $0.44 \pm 0.05 \mathrm{~d}$ & $0.43 \pm 1.1 \mathrm{a}$ & $0.06 \pm 0.01 \mathrm{a}, \mathrm{b}$ \\
\hline & 100 & $5.21 \pm 1.2 \mathrm{c}$ & $0.12 \pm 0.07 \mathrm{a}$ & $0.29 \pm 0.4 \mathrm{a}$ & $0.02 \pm 0.06 \mathrm{a}$ \\
\hline \multirow{5}{*}{ 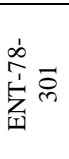 } & 0 & $12.2 \pm 1.1 \mathrm{~h}$ & $1.46 \pm 0.02 \mathrm{k}$ & $1.24 \pm 0.8 \mathrm{e}$ & $0.13 \pm 0.04 \mathrm{c}$ \\
\hline & 25 & $10.4 \pm 1.3 \mathrm{~g}$ & $0.39 \pm 0.07 \mathrm{~d}$ & $0.92 \pm 0.9 \mathrm{~d}$ & $0.11 \pm 0.03 \mathrm{c}$ \\
\hline & 50 & $8.87 \pm 1.1 \mathrm{f}$ & $0.30 \pm 0.09 \mathrm{c}$ & $0.98 \pm 0.2 \mathrm{~d}$ & $0.12 \pm 0.07 \mathrm{c}$ \\
\hline & 75 & $7.61 \pm 1.2 \mathrm{e}$ & $0.28 \pm 0.07 \mathrm{c}$ & $0.56 \pm 0.5 \mathrm{~b}$ & $0.05 \pm 0.05 \mathrm{a}$ \\
\hline & 100 & $6.77 \pm 1.2 \mathrm{e}$ & $0.20 \pm 0.02 \mathrm{a}$ & $0.34 \pm 0.1 \mathrm{a}$ & $0.11 \pm 0.09 \mathrm{c}$ \\
\hline
\end{tabular}

* Means having the same letter in a column were not significantly different by Duncan's multiple range test $P<0.05$ level. 
Shoot and root growth inhibition is a common response to salinity and plant growth is one of the most important agricultural indices of salt stress tolerance as indicated by various researchers [18 - 21]. This shows that a mild salinity can adversely affect the growth of Sesamum. However, the genotypes ' Prachi' ,'Kanaka' and 'KM-13' showed higher dry weight of shoot and root in the presence of $\mathrm{NaCl}$ and, therefore, were categorized as salt-tolerant (Table 1).

Although information is lacking on sesame, the adverse effect of salinity on plant biomass has earlier been observed in a number of plant species e.g. cotton [22], linseed [23], bean [24], maize [25] tetraploid wheat [26], pea [27], alfalfa [28] and sorghum [29]. Munns and Tester [19] reported that the salinity reduces the ability of plants to uptake water which subsequently leads to a reduction in growth rate along with a chain of metabolic changes. There are also reductions in plant biomass attributes under stressful conditions because of a reduced photosynthetic activity per unit leaf area [24], additional cost to exclude or compartmentalize salts within the cells and the salt-induced damage to the plant cells and tissues [27].

The protein, proline and total carbohydrate content were increased in seedlings grown in the soil having $\mathrm{NaCl}$ as compare with seedlings grown without application of $\mathrm{NaCl}$ (Tables 2-4).

Table 2: Protein content (mg per $\mathrm{g}$ fresh weight basis) of ten genotypes of Sesamum indicum $\mathrm{L}$. grown in soil with application of different concentrations of $\mathrm{NaCl}$.

\begin{tabular}{|c|c|c|c|c|}
\hline \multirow[b]{2}{*}{ 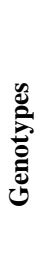 } & \multirow{2}{*}{ 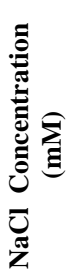 } & \multicolumn{3}{|c|}{ 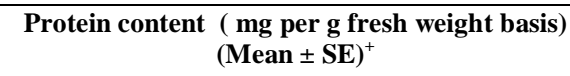 } \\
\hline & & $\begin{array}{l}15 \text { days of } \\
\text { treatment }\end{array}$ & $\begin{array}{l}30 \text { days of } \\
\text { treatment }\end{array}$ & $\begin{array}{l}45 \text { days of } \\
\text { treatment }\end{array}$ \\
\hline \multirow{5}{*}{$\begin{array}{l}\frac{1}{1} \\
\infty \\
\frac{1}{N} \\
\frac{1}{\sim}\end{array}$} & 0 & $6.4 \pm 0.4 \mathrm{a}$ & $8.8 \pm 0.5 \mathrm{a}$ & $10.0 \pm 0.4 \mathrm{~b}$ \\
\hline & 25 & $8.0 \pm 0.5 \mathrm{~b}$ & $10.4 \pm 0.8 \mathrm{~b}$ & $13.7 \pm 0.8 \mathrm{~d}$ \\
\hline & 50 & $12.0 \pm 0.6 \mathrm{~d}$ & $17.8 \pm 0.3 \mathrm{e}$ & * \\
\hline & 75 & $18.6 \pm 0.5 \mathrm{~g}$ & $26.2 \pm 0.6 \mathrm{i}$ & * \\
\hline & 100 & $24.0 \pm 0.7 \mathrm{j}$ & $31.6 \pm 1.2 \mathrm{k}$ & * \\
\hline \multirow{5}{*}{$\begin{array}{l}\text { P } \\
\text { o } \\
\text { is }\end{array}$} & 0 & $8.8 \pm 0.2 \mathrm{~b}$ & $19.0 \pm 0.7 \mathrm{f}$ & $8.0 \pm 0.7 \mathrm{a}$ \\
\hline & 25 & $8.0 \pm 0.4 \mathrm{~b}$ & $17.2 \pm 0.8 \mathrm{e}$ & $14.6 \pm 0.8 \mathrm{~d}, \mathrm{e}$ \\
\hline & 50 & $17.2 \pm 0.8 \mathrm{~g}$ & $23.6 \pm 1.4 \mathrm{~h}$ & $*$ \\
\hline & 75 & $18.4 \pm 0.9 \mathrm{~g}$ & $28.6 \pm 0.7 \mathrm{j}$ & * \\
\hline & 100 & $29.6 \pm 0.8 \mathrm{~m}$ & $30.0 \pm 1.0 \mathrm{k}$ & * \\
\hline \multirow{5}{*}{ 总 } & 0 & $8.6 \pm 0.3 \mathrm{~b}$ & $14.0 \pm 0.8 \mathrm{~d}$ & $21.7 \pm 0.5 \mathrm{~h}$ \\
\hline & 25 & $17.4 \pm 0.9 \mathrm{~g}$ & $24.6 \pm 1.2 \mathrm{~h}$ & $29.6 \pm 0.7 \mathrm{j}$ \\
\hline & 50 & $21.2 \pm 1.0 \mathrm{~h}$ & $25.8 \pm 1.1 \mathrm{~h}, \mathrm{i}$ & $*$ \\
\hline & 75 & $30.4 \pm 1.2 \mathrm{~m}$ & $34.8 \pm 1.2 \mathrm{~m}$ & * \\
\hline & 100 & $37.6 \pm 1.2 \mathrm{n}$ & $40.4 \pm 1.0 \mathrm{n}$ & $*$ \\
\hline \multirow{5}{*}{ 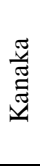 } & 0 & $7.8 \pm 0.6 \mathrm{~b}$ & $12.8 \pm 0.8 \mathrm{c}$ & $17.0 \pm 0.6 \mathrm{f}$ \\
\hline & 25 & $9.4 \pm 0.7 \mathrm{c}$ & $14.4 \pm 0.7 \mathrm{c}, \mathrm{d}$ & $22.2 \pm 0.9 \mathrm{~h}$ \\
\hline & 50 & $9.8 \pm 0.6 \mathrm{c}$ & $15.6 \pm 0.6 \mathrm{~d}$ & $*$ \\
\hline & 75 & $12.4 \pm 0.8 \mathrm{~d}$ & $19.0 \pm 1.6 \mathrm{f}$ & * \\
\hline & 100 & $26.4 \pm 1.7 \mathrm{k}$ & $35.8 \pm 0.7 \mathrm{~m}$ & * \\
\hline \multirow{5}{*}{ 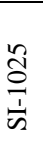 } & 0 & $6.6 \pm 0.7 \mathrm{a}$ & $9.8 \pm 0.8 \mathrm{~b}$ & $10.8 \pm 0.6 \mathrm{~b}$ \\
\hline & 25 & $13.2 \pm 1.0 \mathrm{~d}$ & $21.2 \pm 2.3 \mathrm{~g}$ & $25.6 \pm 1.2 \mathrm{i}$ \\
\hline & 50 & $18.0 \pm 0.8 \mathrm{~g}$ & $28.6 \pm 1.0 \mathrm{j}$ & * \\
\hline & 75 & $26.4 \pm 0.9 \mathrm{k}$ & $32.8 \pm 1.21$ & * \\
\hline & 100 & $28.8 \pm 1.11$ & $33.2 \pm 0.91$ & * \\
\hline
\end{tabular}

\begin{tabular}{|c|c|c|c|c|}
\hline \multirow{5}{*}{$\begin{array}{l}n \\
\stackrel{1}{1} \\
i \\
n\end{array}$} & 0 & $8.4 \pm 0.5 \mathrm{~b}$ & $13.2 \pm 0.7 \mathrm{c}$ & $12.2 \pm 0.6 \mathrm{c}$ \\
\hline & 25 & $10.6 \pm 0.9 \mathrm{c}$ & $16.8 \pm 0.8 \mathrm{e}$ & $19.4 \pm 0.8 \mathrm{~g}$ \\
\hline & 50 & $16.8 \pm 1.2 \mathrm{f}$ & $31.2 \pm 1.0 \mathrm{k}$ & * \\
\hline & 75 & $26.6 \pm 1.5 \mathrm{k}$ & $32.2 \pm 1.31$ & $*$ \\
\hline & 100 & $29.4 \pm 1.4 \mathrm{~m}$ & $33.4 \pm 1.21$ & * \\
\hline \multirow{5}{*}{$\stackrel{m}{\sum_{1}^{1}}$} & 0 & $5.8 \pm 0.7 \mathrm{a}$ & $7.7 \pm 0.6 \mathrm{a}$ & $10.2 \pm 0.5 \mathrm{~b}$ \\
\hline & 25 & $6.4 \pm 0.5 \mathrm{a}$ & $8.2 \pm 0.7 \mathrm{a}$ & $9.6 \pm 0.6 \mathrm{~b}$ \\
\hline & 50 & $11.6 \pm 0.8 \mathrm{~d}$ & $18.2 \pm 0.6 \mathrm{f}$ & * \\
\hline & 75 & $11.8 \pm 0.7 \mathrm{~d}$ & $23.6 \pm 0.8 \mathrm{~h}$ & $*$ \\
\hline & 100 & $19.6 \pm 0.9 \mathrm{~h}$ & $24.0 \pm 1.0 \mathrm{~h}$ & $*$ \\
\hline \multirow{5}{*}{$\begin{array}{l}\frac{1}{1} \\
\frac{1}{\delta} \\
\stackrel{1}{1} \\
\stackrel{1}{=}\end{array}$} & 0 & $10.6 \pm 0.8 \mathrm{c}$ & $14.2 \pm 0.4 \mathrm{c}, \mathrm{d}$ & $14.4 \pm 0.7 \mathrm{~d}$ \\
\hline & 25 & $16.4 \pm 0.6 \mathrm{f}$ & $19.6 \pm 0.6 \mathrm{f}$ & $7.0 \pm 0.7 \mathrm{a}$ \\
\hline & 50 & $20.4 \pm 0.7 \mathrm{~h}$ & $27.6 \pm 1.1 \mathrm{j}$ & $*$ \\
\hline & 75 & $22.4 \pm 0.9 \mathrm{i}$ & $29.6 \pm 1.4 \mathrm{k}$ & $*$ \\
\hline & 100 & $28.0 \pm 1.21$ & $34.0 \pm 0.8 \mathrm{~m}$ & $*$ \\
\hline \multirow{5}{*}{$\begin{array}{l}\stackrel{\aleph}{\sigma} \\
\frac{1}{\omega}\end{array}$} & 0 & $7.5 \pm 0.4 \mathrm{~b}$ & $9.4 \pm 0.6 \mathrm{~b}$ & $13.8 \pm 0.8 \mathrm{~d}$ \\
\hline & 25 & $8.6 \pm 0.6 \mathrm{~b}$ & $11.6 \pm 0.7 \mathrm{c}$ & $15.0 \pm 0.6 \mathrm{e}$ \\
\hline & 50 & $8.8 \pm 0.8 \mathrm{~b}$ & $14.6 \pm 0.6 \mathrm{~d}$ & $*$ \\
\hline & 75 & $10.8 \pm 0.8$ & $15.1 \pm 0.4 \mathrm{~d}$ & $*$ \\
\hline & 100 & $18.6 \pm 0.7 \mathrm{~g}$ & $24.4 \pm 0.8 \mathrm{~h}$ & $*$ \\
\hline \multirow{5}{*}{ 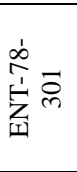 } & 0 & $8.4 \pm 0.6 \mathrm{~b}$ & $12.2 \pm 0.7 \mathrm{c}$ & $14.4 \pm 0.7 \mathrm{~d}, \mathrm{e}$ \\
\hline & 25 & $10.2 \pm 0.5 \mathrm{c}$ & $12.4 \pm 0.8 \mathrm{c}$ & $13.8 \pm 0.8 \mathrm{~d}$ \\
\hline & 50 & $12.6 \pm 0.8 \mathrm{~d}$ & $14.2 \pm 0.8 \mathrm{c}, \mathrm{d}$ & $*$ \\
\hline & 75 & $16.8 \pm 0.7 \mathrm{f}$ & $23.2 \pm 0.9 \mathrm{~h}$ & $*$ \\
\hline & 100 & $27.4 \pm 0.91$ & $34.7 \pm 0.7 \mathrm{~m}$ & $*$ \\
\hline
\end{tabular}

+10 replicates / treatment; repeated twice. *Plant did not survived, Means having the same letter in a column were not significantly different by Duncan's multiple range test $P<0.05$ level.

Table 3: Proline content ( $\mu \mathrm{g}$ per gm fresh weight basis) of ten genotypes of Sesamum indicum $\mathrm{L}$. grown in soil with application of different concentrations of $\mathrm{NaCl}$.

\begin{tabular}{|c|c|c|c|c|}
\hline \multirow{2}{*}{ 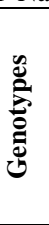 } & \multirow{2}{*}{ 己 } & \multicolumn{3}{|c|}{ 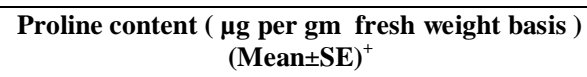 } \\
\hline & & $\begin{array}{l}15 \text { days of } \\
\text { treatment }\end{array}$ & $\begin{array}{l}30 \text { days of } \\
\text { treatment }\end{array}$ & $\begin{array}{l}45 \text { days of } \\
\text { treatment }\end{array}$ \\
\hline \multirow{5}{*}{ 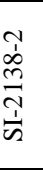 } & 0 & $3.10 \pm 0.5 \mathrm{~b}$ & $6.16 \pm 0.4 \mathrm{~b}$ & $9.50 \pm 0.5 \mathrm{c}$ \\
\hline & 25 & $3.46 \pm 0.3 \mathrm{~b}$ & $10.4 \pm 0.8 \mathrm{~d}$ & $13.4 \pm 0.8 \mathrm{e}$ \\
\hline & 50 & $7.73 \pm 0.6 \mathrm{f}$ & $16.2 \pm 0.7 \mathrm{f}$ & $*$ \\
\hline & 75 & $14.2 \pm 0.4 \mathrm{i}$ & $19.5 \pm 0.6 \mathrm{~h}$ & $*$ \\
\hline & 100 & $27.0 \pm 1.1 \mathrm{n}$ & $35.5 \pm 1.1 \mathrm{p}$ & $*$ \\
\hline \multirow{5}{*}{ 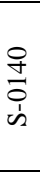 } & 0 & $5.16 \pm 0.3 \mathrm{~d}$ & $5.20 \pm 0.4 \mathrm{a}$ & $8.07 \pm 0.7 \mathrm{~b}$ \\
\hline & 25 & $6.92 \pm 0.7 \mathrm{e}$ & $5.54 \pm 0.7 \mathrm{a}$ & $12.2 \pm 0.8 \mathrm{~d}$ \\
\hline & 50 & $8.46 \pm 0.4 \mathrm{~g}$ & $12.3 \pm 0.6 \mathrm{e}$ & $*$ \\
\hline & 75 & $12.6 \pm 0.8 \mathrm{~h}$ & $23.2 \pm 0.8 \mathrm{j}$ & $*$ \\
\hline & 100 & $25.8 \pm 0.7 \mathrm{~m}$ & $30.6 \pm 0.7 \mathrm{n}$ & $*$ \\
\hline \multirow{5}{*}{$\begin{array}{l}\ddot{z} \\
\overrightarrow{0} \\
\tilde{D}\end{array}$} & 0 & $2.24 \pm 0.6 \mathrm{a}$ & $8.00 \pm 0.5 \mathrm{c}$ & $9.42 \pm 0.8 \mathrm{c}$ \\
\hline & 25 & $3.80 \pm 0.5 \mathrm{~b}$ & $8.31 \pm 0.8 \mathrm{c}$ & $13.5 \pm 0.6 \mathrm{e}$ \\
\hline & 50 & $8.16 \pm 0.6 \mathrm{~g}$ & $12.5 \pm 0.4 \mathrm{e}$ & $*$ \\
\hline & 75 & $14.2 \pm 0.8 \mathrm{i}$ & $18.0 \pm 0.3 \mathrm{~g}$ & * \\
\hline & 100 & $21.1 \pm 0.61$ & $27.6 \pm 0.5 \quad 1$ & * \\
\hline \multirow{5}{*}{$\begin{array}{l}\frac{\widetilde{J}}{\widetilde{\Xi}} \\
\text { ت्ञ }\end{array}$} & 0 & $2.08 \pm 0.4 \mathrm{a}$ & $8.65 \pm 0.2 \mathrm{c}$ & $12.2 \pm 0.5 \mathrm{~d}$ \\
\hline & 25 & $4.16 \pm 0.8 \mathrm{c}$ & $10.4 \pm 0.9 \mathrm{~d}$ & $17.6 \pm 0.7 \mathrm{f}$ \\
\hline & 50 & $12.4 \pm 0.6 \mathrm{~h}$ & $17.6 \pm 1.2 \mathrm{~g}$ & * \\
\hline & 75 & $17.8 \pm 0.7 \mathrm{j}$ & $21.8 \pm 0.8 \mathrm{i}$ & $*$ \\
\hline & 100 & $22.2 \pm 0.91$ & $33.2 \pm 1.0 \mathrm{o}$ & $*$ \\
\hline \multirow{5}{*}{ 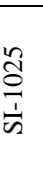 } & 0 & $3.46 \pm 0.8 \mathrm{~b}$ & $4.80 \pm 0.8 \mathrm{a}$ & $5.54 \pm 0.8 \mathrm{a}$ \\
\hline & 25 & $5.07 \pm 0.4 \mathrm{~d}$ & $6.93 \pm 0.7 \mathrm{~b}$ & $16.9 \pm 0.7 \mathrm{f}$ \\
\hline & 50 & $12.0 \pm 0.8 \mathrm{~h}$ & $15.2 \pm 0.6 \mathrm{f}$ & $*$ \\
\hline & 75 & $18.1 \pm 0.5 \mathrm{k}$ & $24.3 \pm 0.3 \mathrm{k}$ & $*$ \\
\hline & 100 & $21.2 \pm 0.71$ & $29.7 \pm 1.3 \mathrm{~m}$ & * \\
\hline \multirow{4}{*}{$\begin{array}{l}\stackrel{n}{\stackrel{N}{1}} \\
\stackrel{i}{n}\end{array}$} & 0 & $4.16 \pm 0.6 \mathrm{c}$ & $6.58 \pm 0.8 \mathrm{~b}$ & $10.0 \pm 0.6 \mathrm{c}$ \\
\hline & 25 & $5.88 \pm 0.8 \mathrm{~d}$ & $7.27 \pm 0.9 \mathrm{~b}$ & $16.9 \pm 0.7 \mathrm{f}$ \\
\hline & 50 & $6.23 \pm 0.5 \mathrm{~d}$ & $15.5 \pm 0.6 \mathrm{f}$ & * \\
\hline & 75 & $13.3 \pm 0.4 \mathrm{~h}$ & $17.6 \pm 0.7 \mathrm{~g}$ & * \\
\hline
\end{tabular}




\begin{tabular}{|c|c|c|c|c|}
\hline & 100 & $17.6 \pm 0.8 \mathrm{j}$ & $27.6 \pm 0.91$ & $*$ \\
\hline \multirow{5}{*}{$\frac{m}{\sum^{1}}$} & 0 & $4.16 \pm 0.4 \mathrm{c}$ & $6.92 \pm 0.7 \mathrm{~b}$ & $9.4 \pm 0.8 \mathrm{c}$ \\
\hline & 25 & $6.42 \pm 0.6 \mathrm{~d}$ & $7.27 \pm 0.5 \mathrm{c}$ & $14.2 \pm 0.9 \mathrm{e}$ \\
\hline & 50 & $12.8 \pm 0.4 \mathrm{~h}$ & $16.5 \pm 0.6 \mathrm{f}$ & * \\
\hline & 75 & $19.4 \pm 0.8 \mathrm{k}$ & $24.8 \pm 0.8 \mathrm{k}$ & * \\
\hline & 100 & $27.1 \pm 0.9 \mathrm{n}$ & $32.9 \pm 0.7 \mathrm{o}$ & * \\
\hline \multirow{5}{*}{$\begin{array}{l}\frac{1}{1} \\
\frac{1}{\delta} \\
0 \\
1 \\
\mathscr{2}\end{array}$} & 0 & $7.80 \pm 0.6 \mathrm{f}$ & $10.7 \pm 0.6 \mathrm{~d}$ & $12.1 \pm 0.7 \mathrm{~d}$ \\
\hline & 25 & $12.8 \pm 0.8 \mathrm{~h}$ & $15.2 \pm 0.7 \mathrm{f}$ & $23.4 \pm 0.9 \mathrm{~h}$ \\
\hline & 50 & $14.8 \pm 0.7 \mathrm{i}$ & $20.4 \pm 0.8 \mathrm{~h}$ & * \\
\hline & 75 & $21.2 \pm 0.41$ & $27.3 \pm 1.21$ & * \\
\hline & 100 & $24.5 \pm 0.8 \mathrm{~m}$ & $33.3 \pm 1.0 \mathrm{o}$ & * \\
\hline \multirow{5}{*}{$\frac{\stackrel{\sigma}{\sigma}}{\frac{1}{n}}$} & 0 & $4.16 \pm 0.6 \mathrm{c}$ & $10.0 \pm 0.6 \mathrm{~d}$ & $13.7 \pm 0.9 \mathrm{e}$ \\
\hline & 25 & $9.35 \pm 0.7 \mathrm{~g}$ & $12.7 \pm 0.7 \mathrm{e}$ & $23.2 \pm 0.8 \mathrm{~h}$ \\
\hline & 50 & $7.61 \pm 0.8 \mathrm{f}$ & $15.5 \pm 0.5 \mathrm{f}$ & * \\
\hline & 75 & $16.8 \pm 0.7 \mathrm{j}$ & $21.8 \pm 0.6 \mathrm{i}$ & $*$ \\
\hline & 100 & $26.2 \pm 0.9 \mathrm{n}$ & $29.0 \pm 1.3 \mathrm{~m}$ & * \\
\hline \multirow{4}{*}{ 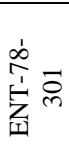 } & 0 & $7.16 \pm 0.8 \mathrm{f}$ & $9.10 \pm 0.7 \mathrm{~d}$ & $11.7 \pm 0.7 \mathrm{~d}$ \\
\hline & 25 & $7.61 \pm 0.5 \mathrm{f}$ & $10.7 \pm 0.8 \mathrm{~d}$ & $18.3 \pm 0.6 \mathrm{~g}$ \\
\hline & 50 & $14.5 \pm 0.5 \mathrm{i}$ & $18.3 \pm 0.7 \mathrm{~g}$ & * \\
\hline & 75 & $18.2 \pm 0.8 \mathrm{k}$ & $27.3 \pm 0.91$ & * \\
\hline & 100 & $25.5 \pm$ & $31.0+1.2 \mathrm{n}$ & \\
\hline
\end{tabular}

*Plant did not survived, ${ }^{+} 10$ replicates / treatment; repeated twice. Means having the same letter in a column were not significantly different by Duncan's multiple range test $P<0.05$ level.

Higher proline accumulation (27.12 $\mathrm{mg} / \mathrm{gm})$ was observed in genotype ' $\mathrm{KM}-13$ ' grown at $100 \mathrm{mM}$ of $\mathrm{NaCl}$ treatment. This genotype successfully tolerate at higher salinity level by accumulating more proline in leaves. Protein content was higher in genotypes 'IS-607-1-84' (10.6 mg per gm), 'S-0140' (8.8 $\mathrm{mg}$ per gm) and 'Prachi' (8.6 $\mathrm{mg}$ per gm) as compared to other genotypes. Furthermore, increase of protein content with increase of $\mathrm{NaCl}$ concentration in all the genotypes. After 45 days of treatment, all the plants were died except in plant grown in soil without treatment of $\mathrm{NaCl}$ as well as $25 \mathrm{mM} \mathrm{NaCl}$. The total carbohydrates contents increased in all the ten genotypes of Sesamum in presence of $\mathrm{NaCl}$ (Table. 4).

Table 4: Total carbohydrate content (mg per gm fresh weight basis) of ten genotypes of Sesamum indicum L. grown in soil with application of different concentrations of $\mathrm{NaCl}$.

\begin{tabular}{|c|c|c|c|c|}
\hline \multirow{2}{*}{ 递 } & \multirow{2}{*}{ 乙 } & \multicolumn{3}{|c|}{$\begin{array}{c}\text { Carbohydrate content }(\mathrm{mg} \text { per gm fresh weight } \\
\text { basis) } \\
(\text { Mean } \pm \mathrm{SE})^{+}\end{array}$} \\
\hline & & $\begin{array}{l}15 \text { days of } \\
\text { treatment }\end{array}$ & $\begin{array}{l}\text { 30 days of } \\
\text { treatment }\end{array}$ & $\begin{array}{l}45 \text { days of } \\
\text { treatment }\end{array}$ \\
\hline \multirow{5}{*}{$\begin{array}{l}\stackrel{N}{\infty} \\
\stackrel{\infty}{\sim} \\
\frac{N}{\sim} \\
\frac{1}{n}\end{array}$} & 0 & $26.2 \pm 0.9 \mathrm{j}$ & $34.6 \pm 1.1 \mathrm{e}$ & $24.2 \pm 0.9 \mathrm{a}$ \\
\hline & 25 & $29.4 \pm 1.3 \mathrm{k}$ & $34.2 \pm 0.9 \mathrm{e}$ & $46.4 \pm 1.5 \mathrm{e}$ \\
\hline & 50 & $36.4 \pm 1.2 \mathrm{n}$ & $42.4 \pm 1.5 \mathrm{~h}$ & $*$ \\
\hline & 75 & $39.1 \pm 0.8 \mathrm{p}$ & $43.8 \pm 1.8 \mathrm{i}$ & $*$ \\
\hline & 100 & $42.4 \pm 1.1 \mathrm{q}$ & $48.6 \pm 1.4 \mathrm{j}$ & $*$ \\
\hline \multirow{5}{*}{$\begin{array}{l}\text { +⿱ } \\
\text { o } \\
\text { ì }\end{array}$} & 0 & $12.2 \pm 0.5 \mathrm{c}$ & $58.2 \pm 1.3 \mathrm{~m}$ & $56.7 \pm 1.2 \mathrm{f}$ \\
\hline & 25 & $24.2 \pm 0.6 \mathrm{i}$ & $42.6 \pm 1.7 \mathrm{~h}$ & $42.8 \pm 1.5 \mathrm{~d}$ \\
\hline & 50 & $26.3 \pm 0.7 \mathrm{j}$ & $56.4 \pm 1.51$ & $*$ \\
\hline & 75 & $20.2 \pm 0.8 \mathrm{~g}$ & $62.0 \pm 1.3 \mathrm{o}$ & $*$ \\
\hline & 100 & $18.4 \pm 0.7 \mathrm{f}$ & $34.2 \pm 1.2 \mathrm{e}$ & $*$ \\
\hline \multirow{5}{*}{$\begin{array}{l}\ddot{\Xi} \\
\bar{\Xi} \\
\tilde{D}\end{array}$} & 0 & $20.6 \pm 1.1 \mathrm{~g}$ & $28.4 \pm 1.3 \mathrm{c}$ & $37.4 \pm 1.8 \mathrm{c}$ \\
\hline & 25 & $12.4 \pm 0.5 \mathrm{c}$ & $32.5 \pm 1.7 \mathrm{~d}$ & $42.2 \pm 1.4 \mathrm{~d}$ \\
\hline & 50 & $24.1 \pm 0.6 \mathrm{i}$ & $36.6 \pm 1.2 \mathrm{f}$ & $*$ \\
\hline & 75 & $24.8 \pm 0.8 \mathrm{i}$ & $36.2 \pm 1.6 \mathrm{f}$ & $*$ \\
\hline & 100 & $26.5 \pm 0.9 \mathrm{j}$ & $38.4 \pm 1.3 \mathrm{~g}$ & $*$ \\
\hline \multirow{2}{*}{ 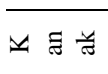 } & 0 & $16.2 \pm 0.6 \mathrm{e}$ & $56.5 \pm 1.71$ & $34.5 \pm 1.7 \mathrm{~b}$ \\
\hline & 25 & $26.3 \pm 0.5 \mathrm{j}$ & $62.2 \pm 1.5 \mathrm{o}$ & $54.3 \pm 1.6 \mathrm{f}$ \\
\hline
\end{tabular}

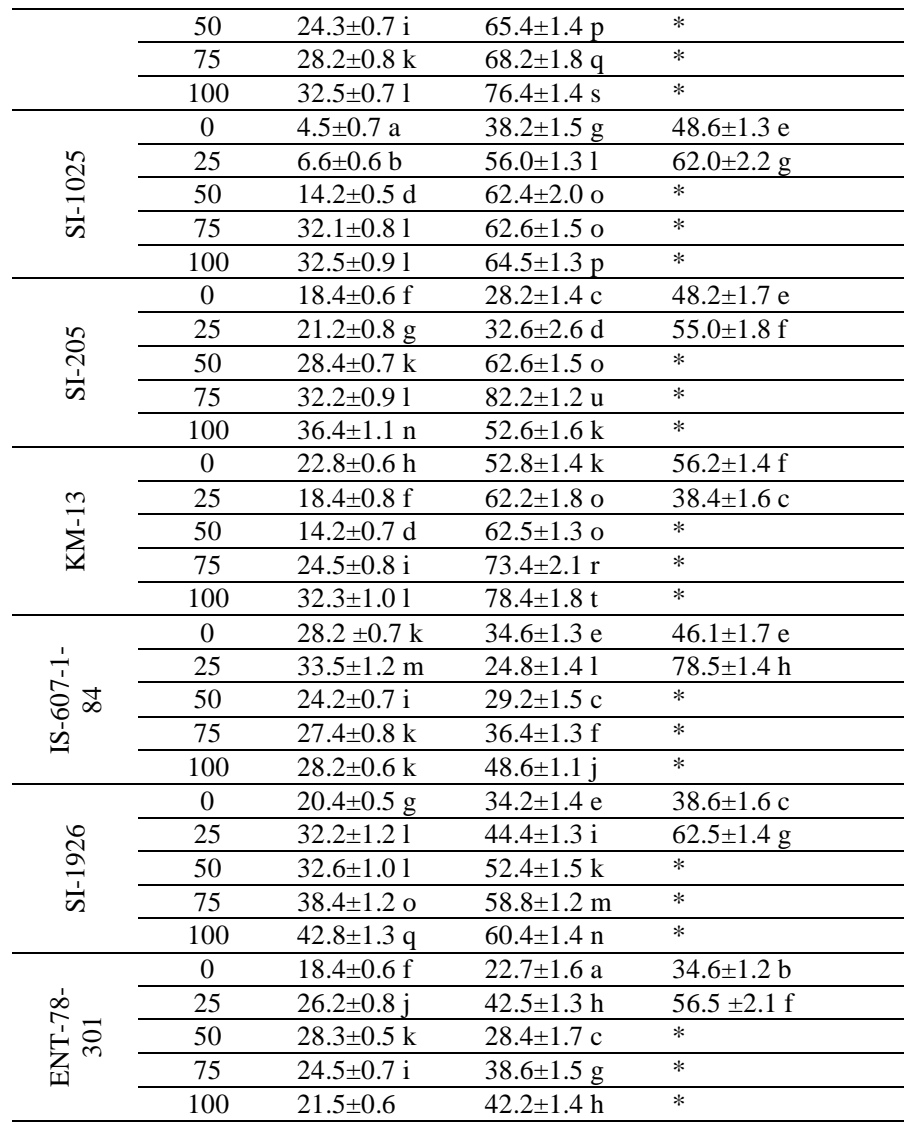

*Plant did not survived, ${ }^{+} 10$ replicates / treatment; repeated twice. Means having the same letter in a column were not significantly different by Duncan's multiple range test $P<0.05$ level.

Proline and total carbohydrates help osmotic adjustment during stress and protect native structure of macromolecules and membranes during extreme dehydration. Rise in total carbohydrates levels in salt-treated genotypes may contribute towards better adaptation to salinity. The proline is one of the prevalent osmolytes that are commonly found in high concentrations when plants are exposed to salt stress [19]. The exact role of proline with regard to plant's response to environmental stresses is rather controversial [30]. Proline accumulation in plant cells might be due to an increase in proteolysis or a decrease in protein synthesis [31]. Accumulation of proline under stress conditions can protect the cell by stabilizing sub cellular structures (e.g. proteins and enzymes) and buffering the cellular redox potential [32]. Besides its role as an osmolyte, proline can also confer enzyme protection and increase membrane stability under various conditions [23]. In present study, the higher proline accumulation is found at $100 \mathrm{mM}$ of $\mathrm{NaCl}$ treatment for 15 days in genotype KM-13 and 30 days in genotype ES2138-2. Proline has been shown to accumulate in response to salinity in a number of plant species $[8,23,33]$. Since proline accumulation in the Sesame genotypes was well-correlated to their growth attributes and production of this free amino acid in the salt-tolerant genotypes was more notable, it seems that it plays some protective roles against salt stress in sesame, at least in the genotypes used in this experiment. 
Table 5: Inorganic ion $\left(\mathrm{Na}^{+}, \mathrm{Cl}-, \mathrm{K}^{+}, \mathrm{Ca}^{2+}\right.$ and $\left.\mathrm{Mg}^{2+}\right)$ content in 15 days old seedlings of ten genotypes of Sesamum indicum L. treatment with different concentrations $(0,25,50,75$ and $100 \mathrm{mM})$ of $\mathrm{NaCl}$. Experiment conducted twice with three replications (*Three replicates/treatment; repeated thrice).

\begin{tabular}{|c|c|c|c|c|c|c|c|c|c|c|c|}
\hline \multirow[t]{2}{*}{$\begin{array}{l}\text { Sesamum } \\
\text { inidicum } \\
\text { Vars. }\end{array}$} & \multirow{2}{*}{$\begin{array}{c}\text { Diff. } \\
\text { Conc. } \\
\text { NaCl } \\
(\mathbf{m M}) \\
\end{array}$} & \multicolumn{2}{|c|}{$\begin{array}{c}\mathrm{Na}^{+} \text {Content } \\
(\mathrm{mmol} / \mathrm{g} \text { dry weight }) \\
(\mathrm{Mean} \pm \mathrm{SE})^{*}\end{array}$} & \multicolumn{2}{|c|}{$\begin{array}{c}\text { Cl Content } \\
(\text { mmol/g dry weight }) \\
(\text { Mean } \pm \text { SE)* }\end{array}$} & \multicolumn{2}{|c|}{$\begin{array}{c}\mathbf{K}^{+} \text {Content } \\
(\mathrm{mmol} / \mathrm{g} \text { dry weight }) \\
(\mathrm{Mean} \pm \mathrm{SE})^{*}\end{array}$} & \multicolumn{2}{|c|}{$\begin{array}{c}\mathrm{Ca}^{++} \text {content } \\
(\mathrm{mmol} / \mathrm{g} \text { dry weight }) \\
(\mathrm{Mean} \pm \mathrm{SE})^{*}\end{array}$} & \multicolumn{2}{|c|}{$\begin{array}{c}\mathbf{M g}^{++} \text {content } \\
(\mathrm{mmol} / \mathrm{g} \text { dry weight }) \\
(\mathrm{Mean} \pm \mathrm{SE}) *\end{array}$} \\
\hline & & Shoot & Root & Shoot & Root & Shoot & Root & Shoot & Root & Shoot & Root \\
\hline \multirow{5}{*}{$\begin{array}{l}\tilde{N} \\
\infty \\
\stackrel{1}{N} \\
\frac{1}{n}\end{array}$} & 0 & $1.1 \pm 0.1$ & $3.8 \pm 0.5$ & 0 & 0 & $0.3 \pm 0.01$ & $0.9 \pm 0.02$ & $0.01 \pm 0.01$ & $0.01 \pm 0.00$ & $0.15 \pm 0.04$ & $0.35 \pm 0.02$ \\
\hline & 25 & $1.4 \pm 0.2$ & $4.0 \pm 0.6$ & $0.4 \pm 0.01$ & $1.2 \pm 0.2$ & $0.2 \pm 0.01$ & $0.8 \pm 0.01$ & $0.01 \pm 0.00$ & $0.01 \pm 0.00$ & $0.16 \pm 0.06$ & $0.41 \pm 0.04$ \\
\hline & 50 & $1.2 \pm 0.3$ & $3.7 \pm 0.7$ & $0.3 \pm 0.01$ & $1.0 \pm 0.1$ & $0.2 \pm 0.01$ & $0.7 \pm 0.02$ & $0.01 \pm 0.00$ & $0.02 \pm 0.01$ & $0.16 \pm 0.04$ & $0.61 \pm 0.04$ \\
\hline & 75 & $1.0 \pm 0.1$ & $3.0 \pm 0.3$ & $0.2 \pm 0.01$ & $0.8 \pm 0.01$ & $0.1 \pm 0.00$ & $0.6 \pm 0.02$ & $0.02 \pm 0.01$ & $0.02 \pm 0.00$ & $0.19 \pm 0.05$ & $0.63 \pm 0.05$ \\
\hline & 100 & $0.9 \pm 0.2$ & $2.6 \pm 0.5$ & $0.1 \pm 0.01$ & $0.5 \pm 0.01$ & $0.1 \pm 0.00$ & $0.4 \pm 0.01$ & $0.02 \pm 0.00$ & $0.04 \pm 0.01$ & $0.21 \pm 0.03$ & $0.58 \pm 0.04$ \\
\hline \multirow{5}{*}{ 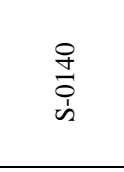 } & 0 & $1.5 \pm 0.1$ & $4.9 \pm 0.6$ & 0 & 0 & $0.6 \pm 0.02$ & $1.0 \pm 0.3$ & $0.01 \pm 0.00$ & $0.01 \pm 0.00$ & $0.10 \pm 0.03$ & $0.53 \pm 0.05$ \\
\hline & 25 & $1.8 \pm 0.3$ & $5.2 \pm 0.8$ & $0.5 \pm 0.02$ & $1.5 \pm 0.3$ & $0.4 \pm 0.01$ & $0.9 \pm 0.04$ & $0.02 \pm 0.01$ & $0.01 \pm 0.00$ & $0.12 \pm 0.04$ & $0.62 \pm 0.04$ \\
\hline & 50 & $2.1 \pm 0.2$ & $5.5 \pm 0.4$ & $0.4 \pm 0.01$ & $1.6 \pm 0.4$ & $0.6 \pm 0.02$ & $0.9 \pm 0.05$ & $0.02 \pm 0.01$ & $0.05 \pm 0.01$ & $0.12 \pm 0.05$ & $0.91 \pm 0.06$ \\
\hline & 75 & $2.5 \pm 0.5$ & $5.8 \pm 0.6$ & $0.4 \pm 0.02$ & $1.4 \pm 0.3$ & $0.5 \pm 0.02$ & $0.7 \pm 0.03$ & $0.03 \pm 0.01$ & $0.08 \pm 0.02$ & $0.14 \pm 0.02$ & $1.03 \pm 0.22$ \\
\hline & 100 & $2.0 \pm 0.2$ & $5.0 \pm 0.4$ & $0.2 \pm 0.01$ & $1.0 \pm 0.2$ & $0.3 \pm 0.01$ & $0.6 \pm 0.02$ & $0.02 \pm 0.00$ & $0.10 \pm 0.03$ & $0.13 \pm 0.03$ & $0.80 \pm 0.07$ \\
\hline \multirow{5}{*}{ 胥 } & 0 & $2.2 \pm 0.1$ & $5.6 \pm 0.5$ & 0 & 0 & $0.4 \pm 0.01$ & $1.2 \pm 0.4$ & $0.01 \pm 0.00$ & $0.01 \pm 0.00$ & $0.14 \pm 0.02$ & $0.61 \pm 0.06$ \\
\hline & 25 & $2.0 \pm 0.3$ & $6.2 \pm 0.6$ & $0.5 \pm 0.01$ & $1.5 \pm 0.2$ & $0.5 \pm 0.02$ & $0.8 \pm 0.02$ & $0.02 \pm 0.00$ & $0.02 \pm 0.01$ & $0.16 \pm 0.01$ & $0.81 \pm 0.05$ \\
\hline & 50 & $2.2 \pm 0.3$ & $6.7 \pm 0.7$ & $0.6 \pm 0.02$ & $1.6 \pm 0.3$ & $0.6 \pm 0.02$ & $0.9 \pm 0.03$ & $0.02 \pm 0.00$ & $0.04 \pm 0.01$ & $0.23 \pm 0.02$ & $1.0 \pm 0.23$ \\
\hline & 75 & $2.1 \pm 0.2$ & $6.9 \pm 0.7$ & $0.4 \pm 0.02$ & $2.3 \pm 0.6$ & $0.8 \pm 0.03$ & $1.0 \pm 0.5$ & $0.03 \pm 0.01$ & $0.08 \pm 0.02$ & $0.25 \pm 0.04$ & $0.92 \pm 0.14$ \\
\hline & 100 & $1.8 \pm 0.1$ & $6.4 \pm 0.5$ & $0.3 \pm 0.01$ & $1.6 \pm 0.5$ & $0.6 \pm 0.02$ & $0.9 \pm 0.03$ & $0.03 \pm 0.01$ & $0.08 \pm 0.04$ & $0.21 \pm 0.06$ & $0.72 \pm 0.11$ \\
\hline \multirow{5}{*}{ 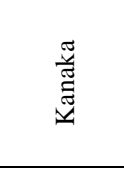 } & 0 & $2.8 \pm 0.2$ & $6.7 \pm 0.4$ & 0 & 0 & $0.5 \pm 0.02$ & $1.5 \pm 0.2$ & $0.01 \pm 0.00$ & $0.01 \pm 0.00$ & $0.15 \pm 0.04$ & $0.56 \pm 0.09$ \\
\hline & 25 & $2.6 \pm 0.2$ & $6.9 \pm 0.3$ & $0.6 \pm 0.02$ & $1.8 \pm 0.2$ & $0.6 \pm 0.03$ & $1.3 \pm 0.5$ & $0.02 \pm 0.00$ & $0.02 \pm 0.01$ & $0.16 \pm 0.02$ & $0.87 \pm 0.08$ \\
\hline & 50 & $2.0 \pm 0.1$ & $7.2 \pm 0.6$ & $0.8 \pm 0.03$ & $2.0 \pm 0.3$ & $0.7 \pm 0.04$ & $1.1 \pm 0.2$ & $0.02 \pm 0.00$ & $0.06 \pm 0.03$ & $0.20 \pm 0.03$ & $0.97 \pm 0.08$ \\
\hline & 75 & $1.8 \pm 0.1$ & $7.4 \pm 0.7$ & $0.6 \pm 0.02$ & $2.6 \pm 0.2$ & $0.5 \pm 0.02$ & $1.0 \pm 0.3$ & $0.03 \pm 0.01$ & $0.08 \pm 0.02$ & $0.23 \pm 0.02$ & $1.10 \pm 0.11$ \\
\hline & 100 & $1.7 \pm 0.1$ & $7.3 \pm 0.8$ & $0.4 \pm 0.01$ & $1.8 \pm 0.1$ & $0.4 \pm 0.01$ & $0.9 \pm 0.06$ & $0.04 \pm 0.01$ & $0.09 \pm 0.04$ & $0.22 \pm 0.01$ & $0.85 \pm 0.07$ \\
\hline \multirow{5}{*}{$\frac{n}{\frac{n}{1}}$} & 0 & $1.2 \pm 0.1$ & $5.0 \pm 0.4$ & 0 & 0 & $0.6 \pm 0.02$ & $1.3 \pm 0.4$ & $0.01 \pm 0.00$ & $0.01 \pm 0.00$ & $0.10 \pm 0.02$ & $0.42 \pm 0.08$ \\
\hline & 25 & $1.4 \pm 0.2$ & $4.9 \pm 0.3$ & $0.5 \pm 0.01$ & $1.2 \pm 0.2$ & $0.6 \pm 0.03$ & $1.2 \pm 0.5$ & $0.01 \pm 0.00$ & $0.01 \pm 0.00$ & $0.13 \pm 0.03$ & $0.66 \pm 0.05$ \\
\hline & 50 & $1.6 \pm 0.2$ & $4.7 \pm 0.3$ & $0.4 \pm 0.02$ & $1.0 \pm 0.2$ & $0.5 \pm 0.01$ & $1.2 \pm 0.3$ & $0.02 \pm 0.00$ & $0.03 \pm 0.01$ & $0.12 \pm 0.04$ & $0.61 \pm 0.05$ \\
\hline & 75 & $1.7 \pm 0.2$ & $3.8 \pm 0.4$ & $0.3 \pm 0.01$ & $0.9 \pm 0.08$ & $0.4 \pm 0.01$ & $1.0 \pm 0.4$ & $0.02 \pm 0.01$ & $0.04 \pm 0.01$ & $0.15 \pm 0.05$ & $0.56 \pm 0.06$ \\
\hline & 100 & $1.3 \pm 0.1$ & $3.0 \pm 0.5$ & $0.1 \pm 0.01$ & $0.7 \pm 0.06$ & $0.3 \pm 0.01$ & $0.9 \pm 0.03$ & $0.03 \pm 0.01$ & $0.04 \pm 0.01$ & $0.15 \pm 0.01$ & $0.58 \pm 0.08$ \\
\hline \multirow{5}{*}{$\frac{n}{\stackrel{n}{n}}$} & 0 & $1.3 \pm 0.1$ & $4.7 \pm 0.4$ & 0 & 0 & $0.5 \pm 0.02$ & $1.1 \pm 0.3$ & $0.01 \pm 0.00$ & $0.01 \pm 0.00$ & $0.11 \pm 0.02$ & $0.45 \pm 0.04$ \\
\hline & 25 & $1.5 \pm 0.2$ & $4.6 \pm 0.3$ & $0.5 \pm 0.01$ & $1.3 \pm 0.2$ & $0.5 \pm 0.02$ & $1.0 \pm 0.2$ & $0.01 \pm 0.00$ & $0.01 \pm 0.00$ & $0.12 \pm 0.02$ & $0.51 \pm 0.05$ \\
\hline & 50 & $1.6 \pm 0.2$ & $4.2 \pm 0.5$ & $0.4 \pm 0.02$ & $1.1 \pm 0.1$ & $0.4 \pm 0.01$ & $1.1 \pm 0.1$ & $0.02 \pm 0.01$ & $0.03 \pm 0.01$ & $0.13 \pm 0.03$ & $0.53 \pm 0.06$ \\
\hline & 75 & $1.2 \pm 0.1$ & $3.8 \pm 0.3$ & $0.2 \pm 0.01$ & $0.6 \pm 0.04$ & $0.3 \pm 0.01$ & $1.1 \pm 0.2$ & $0.02 \pm 0.00$ & $0.04 \pm 0.02$ & $0.13 \pm 0.05$ & $0.44 \pm 0.07$ \\
\hline & 100 & $1.0 \pm 0.1$ & $3.2 \pm 0.2$ & $0.1 \pm 0.01$ & $0.4 \pm 0.03$ & $0.2 \pm 0.01$ & $0.8 \pm 0.05$ & $0.03 \pm 0.01$ & $0.04 \pm 0.01$ & $0.15 \pm 0.04$ & $0.40 \pm 0.04$ \\
\hline \multirow{5}{*}{$\frac{m}{1}$} & 0 & $1.9 \pm 0.2$ & $5.7 \pm 0.5$ & 0 & 0 & $0.3 \pm 0.01$ & $1.7 \pm 0.5$ & $0.01 \pm 0.00$ & $0.01 \pm 0.00$ & $0.12 \pm 0.02$ & $0.24 \pm 0.03$ \\
\hline & 25 & $2.0 \pm 0.2$ & $6.3 \pm 0.6$ & $0.5 \pm 0.01$ & $1.3 \pm 0.3$ & $0.4 \pm 0.01$ & $1.6 \pm 0.4$ & $0.01 \pm 0.00$ & $0.01 \pm 0.00$ & $0.13 \pm 0.01$ & $0.52 \pm 0.06$ \\
\hline & 50 & $2.3 \pm 0.2$ & $6.6 \pm 0.4$ & $0.8 \pm 0.02$ & $1.6 \pm 0.2$ & $0.5 \pm 0.02$ & $1.6 \pm 0.3$ & $0.02 \pm 0.01$ & $0.03 \pm 0.01$ & $0.14 \pm 0.04$ & $0.53 \pm 0.05$ \\
\hline & 75 & $2.1 \pm 0.1$ & $6.2 \pm 0.3$ & $1.0 \pm 0.01$ & $1.8 \pm 0.4$ & $0.4 \pm 0.02$ & $0.9 \pm 0.02$ & $0.03 \pm 0.01$ & $0.05 \pm 0.01$ & $0.13 \pm 0.03$ & $0.82 \pm 0.07$ \\
\hline & 100 & $1.6 \pm 0.2$ & $5.8 \pm 0.5$ & $0.7 \pm 0.02$ & $1.5 \pm 0.2$ & $0.6 \pm 0.03$ & $0.8 \pm 0.05$ & $0.02 \pm 0.00$ & $0.08 \pm 0.02$ & $0.14 \pm 0.02$ & $0.50 \pm 0.06$ \\
\hline \multirow{5}{*}{$\begin{array}{l}\frac{1}{1} \\
\frac{1}{0} \\
\dot{0} \\
\stackrel{1}{2}\end{array}$} & 0 & $1.6 \pm 0.3$ & $4.6 \pm 0.4$ & 0 & 0 & $0.5 \pm 0.02$ & $1.2 \pm 0.2$ & $0.01 \pm 0.00$ & $0.01 \pm 0.00$ & $0.11 \pm 0.01$ & $0.45 \pm 0.04$ \\
\hline & 25 & $1.8 \pm 0.2$ & $4.8 \pm 0.3$ & $0.3 \pm 0.01$ & $1.6 \pm 0.3$ & $0.4 \pm 0.01$ & $1.0 \pm 0.3$ & $0.01 \pm 0.00$ & $0.02 \pm 0.01$ & $0.13 \pm 0.02$ & $0.71 \pm 0.06$ \\
\hline & 50 & $2.0 \pm 0.3$ & $5.0 \pm 0.4$ & $0.7 \pm 0.02$ & $1.3 \pm 0.4$ & $0.3 \pm 0.01$ & $0.8 \pm 0.03$ & $0.03 \pm 0.00$ & $0.03 \pm 0.01$ & $0.14 \pm 0.03$ & $0.82 \pm 0.08$ \\
\hline & 75 & $2.0 \pm 0.2$ & $5.1 \pm 0.3$ & $0.8 \pm 0.01$ & $1.0 \pm 0.2$ & $0.4 \pm 0.01$ & $0.8 \pm 0.02$ & $0.04 \pm 0.01$ & $0.04 \pm 0.02$ & $0.15 \pm 0.06$ & $0.82 \pm 0.05$ \\
\hline & 100 & $1.4 \pm 0.1$ & $4.9 \pm 0.6$ & $0.6 \pm 0.02$ & $0.8 \pm 0.03$ & $0.3 \pm 0.01$ & $0.6 \pm 0.02$ & $0.05 \pm 0.02$ & $0.06 \pm 0.03$ & $0.15 \pm 0.04$ & $0.74 \pm 0.03$ \\
\hline \multirow{5}{*}{$\frac{\mathscr{2}}{\frac{1}{n}}$} & 0 & $2.5 \pm 0.2$ & $6.3 \pm 0.7$ & 0 & 0 & $0.4 \pm 0.02$ & $1.4 \pm 0.4$ & $0.01 \pm 0.00$ & $0.01 \pm 0.00$ & $0.12 \pm 0.02$ & $0.42 \pm 0.04$ \\
\hline & 25 & $2.8 \pm 0.3$ & $6.6 \pm 0.6$ & $0.6 \pm 0.02$ & $1.6 \pm 0.3$ & $0.3 \pm 0.01$ & $1.0 \pm 0.6$ & $0.01 \pm 0.00$ & $0.01 \pm 0.01$ & $0.13 \pm 0.04$ & $0.71 \pm 0.07$ \\
\hline & 50 & $2.4 \pm 0.2$ & $6.8 \pm 0.5$ & $0.8 \pm 0.03$ & $1.3 \pm 0.2$ & $0.7 \pm 0.03$ & $1.2 \pm 0.5$ & $0.01 \pm 0.00$ & $0.03 \pm 0.02$ & $0.15 \pm 0.06$ & $0.81 \pm 0.06$ \\
\hline & 75 & $2.5 \pm 0.2$ & $7.0 \pm 0.4$ & $0.7 \pm 0.02$ & $1.4 \pm 0.2$ & $0.8 \pm 0.04$ & $1.0 \pm 0.2$ & $0.02 \pm 0.01$ & $0.04 \pm 0.01$ & $0.14 \pm 0.05$ & $0.92 \pm 0.07$ \\
\hline & 100 & $2.2 \pm 0.3$ & $5.6 \pm 0.6$ & $0.5 \pm 0.02$ & $1.2 \pm 0.1$ & $0.8 \pm 0.03$ & $0.9 \pm 0.05$ & $0.03 \pm 0.01$ & $0.06 \pm 0.02$ & $0.13 \pm 0.03$ & $0.63 \pm 0.08$ \\
\hline \multirow{5}{*}{ 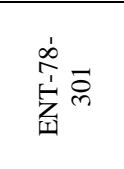 } & 0 & $1.9 \pm 0.1$ & $4.6 \pm 0.4$ & 0 & 0 & $0.6 \pm 0.02$ & $1.3 \pm 0.2$ & $0.01 \pm 0.00$ & $0.01 \pm 0.00$ & $0.11 \pm 0.01$ & $0.51 \pm 0.05$ \\
\hline & 25 & $2.1 \pm 0.2$ & $5.1 \pm 0.3$ & $0.3 \pm 0.01$ & $1.4 \pm 0.4$ & $0.4 \pm 0.01$ & $1.2 \pm 0.3$ & $0.01 \pm 0.00$ & $0.02 \pm 0.01$ & $0.12 \pm 0.03$ & $0.81 \pm 0.05$ \\
\hline & 50 & $2.3 \pm 0.3$ & $5.5 \pm 0.6$ & $0.4 \pm 0.02$ & $1.2 \pm 0.3$ & $0.2 \pm 0.01$ & $1.3 \pm 0.2$ & $0.02 \pm 0.01$ & $0.02 \pm 0.02$ & $0.14 \pm 0.02$ & $0.61 \pm 0.06$ \\
\hline & 75 & $2.6 \pm 0.4$ & $5.7 \pm 0.5$ & $0.3 \pm 0.01$ & $1.3 \pm 0.5$ & $0.1 \pm 0.01$ & $1.0 \pm 0.1$ & $0.02 \pm 0.01$ & $0.03 \pm 0.01$ & $0.13 \pm 0.04$ & $0.73 \pm 0.03$ \\
\hline & 100 & $1.6 \pm 0.2$ & $4.2 \pm 0.4$ & $0.2 \pm 0.01$ & $1.0 \pm 0.2$ & $0.1 \pm 0.01$ & $0.9 \pm 0.05$ & $0.04 \pm 0.01$ & $0.01 \pm 0.00$ & $0.12 \pm 0.04$ & $0.56 \pm 0.05$ \\
\hline
\end{tabular}

A positive relationship between accumulation of proline and stress tolerance was found in Cichorium intybus [1], different cultivars of sesame [33] and tomato [34]. The ion content of the shoot and root depended on the genotype and the concentrations of $\mathrm{NaCl}$ in the medium. $\mathrm{Na}^{+}$and $\mathrm{Cl}^{-}$content were significantly higher in root in each genotype with increasing $\mathrm{NaCl}$ application (Table 5). The tolerant genotypes (i.e. Vars. Kanaka, Parchi, KM-13, SI1926) having high accumulation of $\mathrm{Na}^{+}$content as well as $\mathrm{Cl}^{-}$as compared with medium tolerant (i.e. S-0140, ENT-78-301, IS607-1-84) and low tolerant (i.e. SI-1025, SI-205, SI-2/38-2) genotypes. Salt stress enhanced $\mathrm{Na}^{+}$content in shoot which resulted in decrease of $\mathrm{K}^{+} / \mathrm{Na}^{+}$and $\mathrm{Ca}^{2+} / \mathrm{Na}^{+}$ratio in tolerant genotypes and also increase in medium and low tolerant genotypes (Figs.1A-J). $\mathrm{Na}^{+}$and $\mathrm{Cl}^{-}$were also limits cell elongation and cell differentiation which may lead to the reduction of plant growth, root and shoot lengths in higher concentrations of $\mathrm{NaCl}$. 


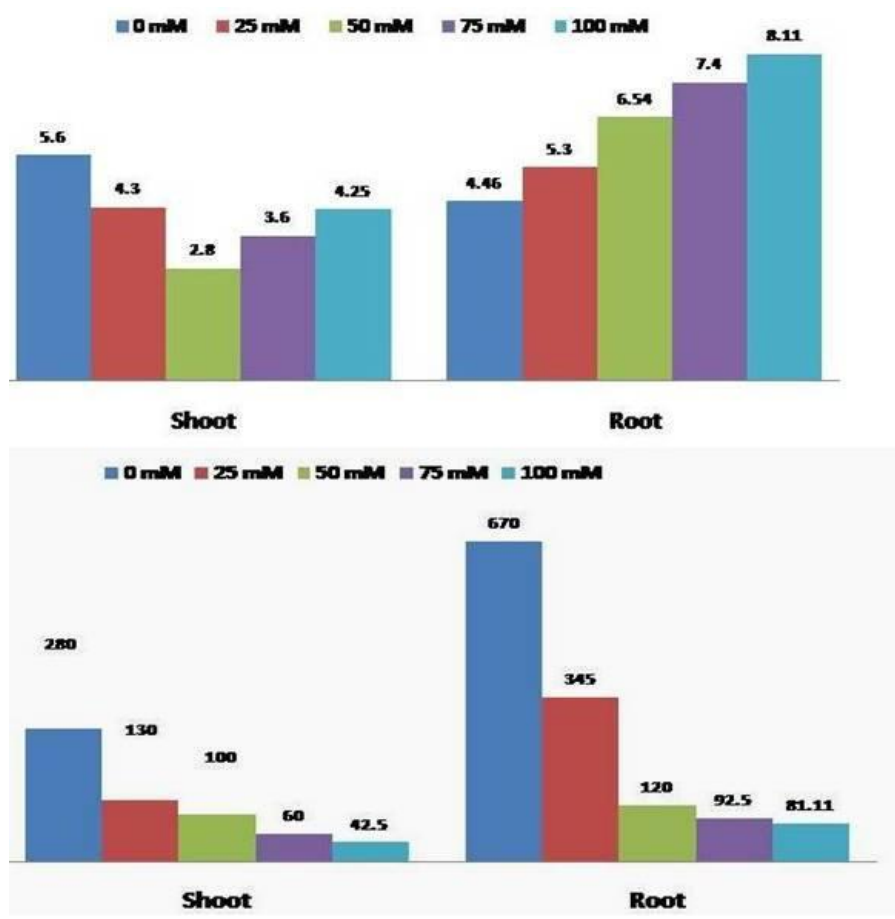

Fig. 1A:
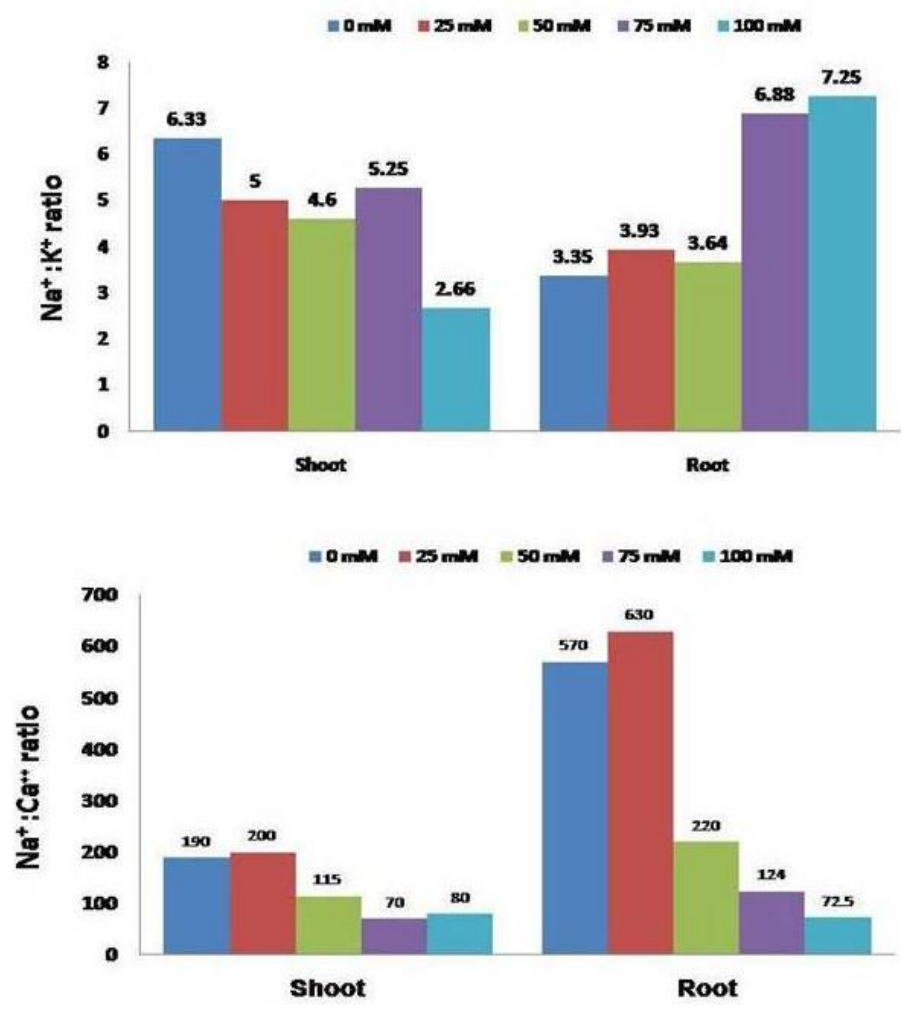

Fig. 1C:

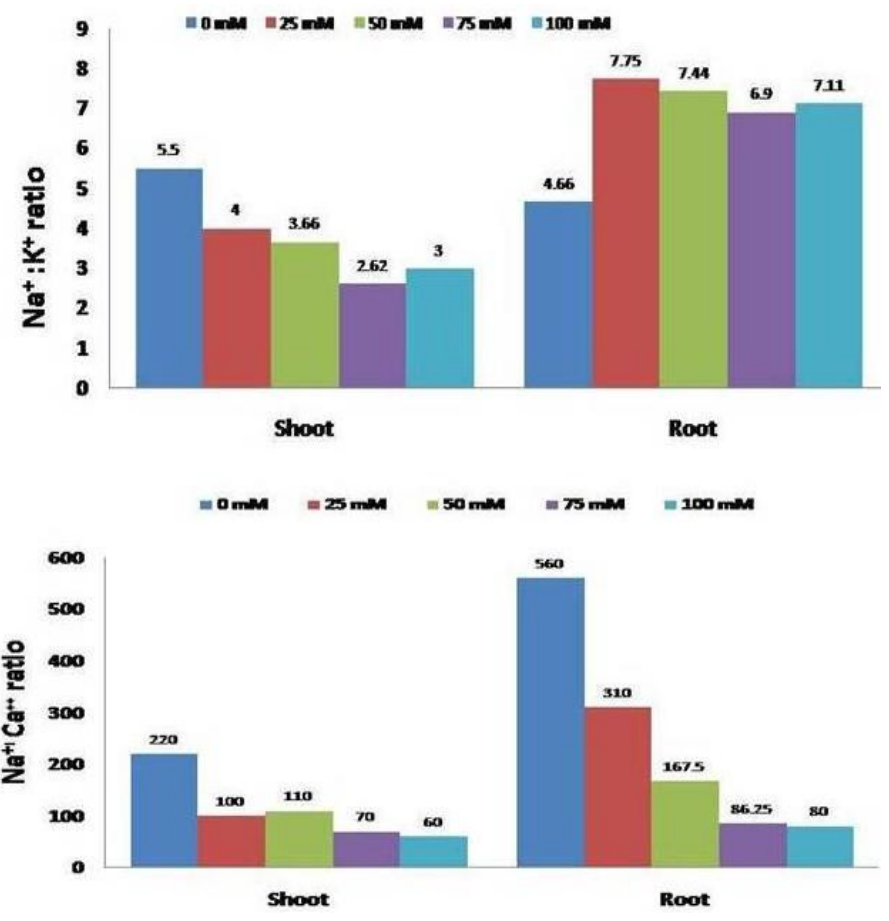

Fig. 1B:
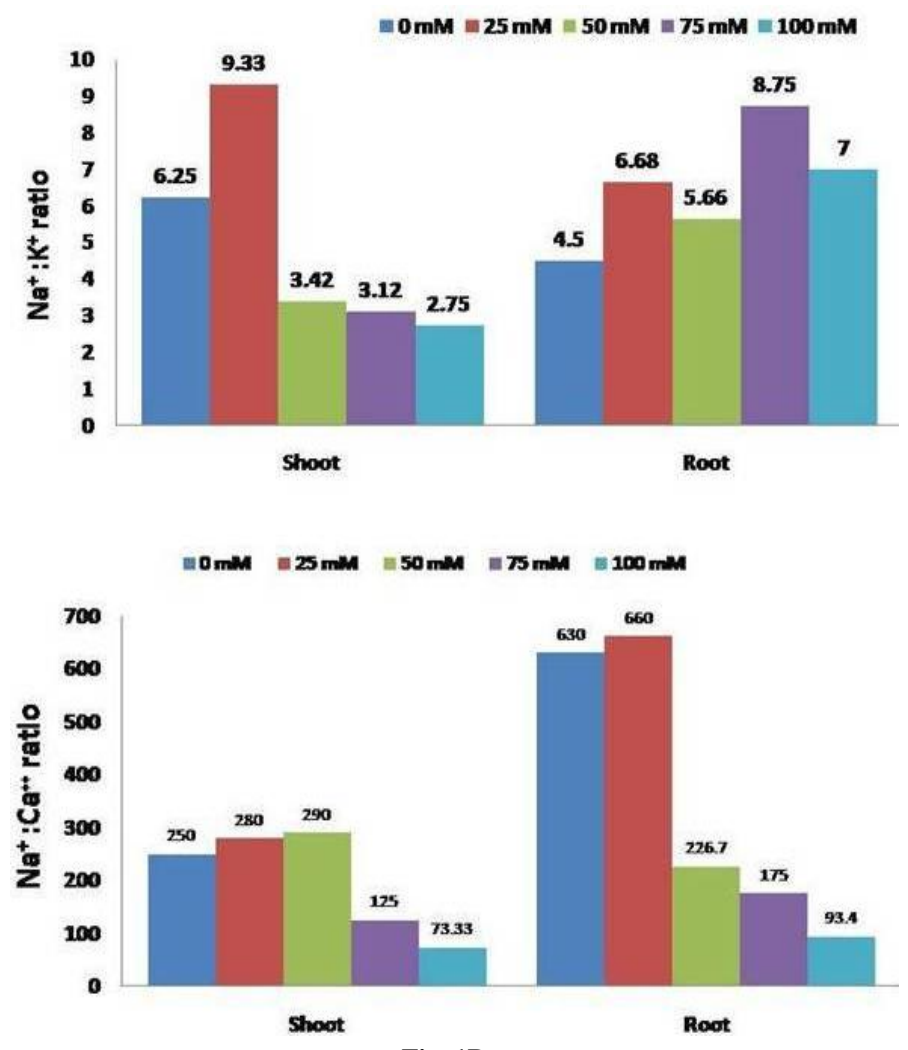

Fig. 1D: 


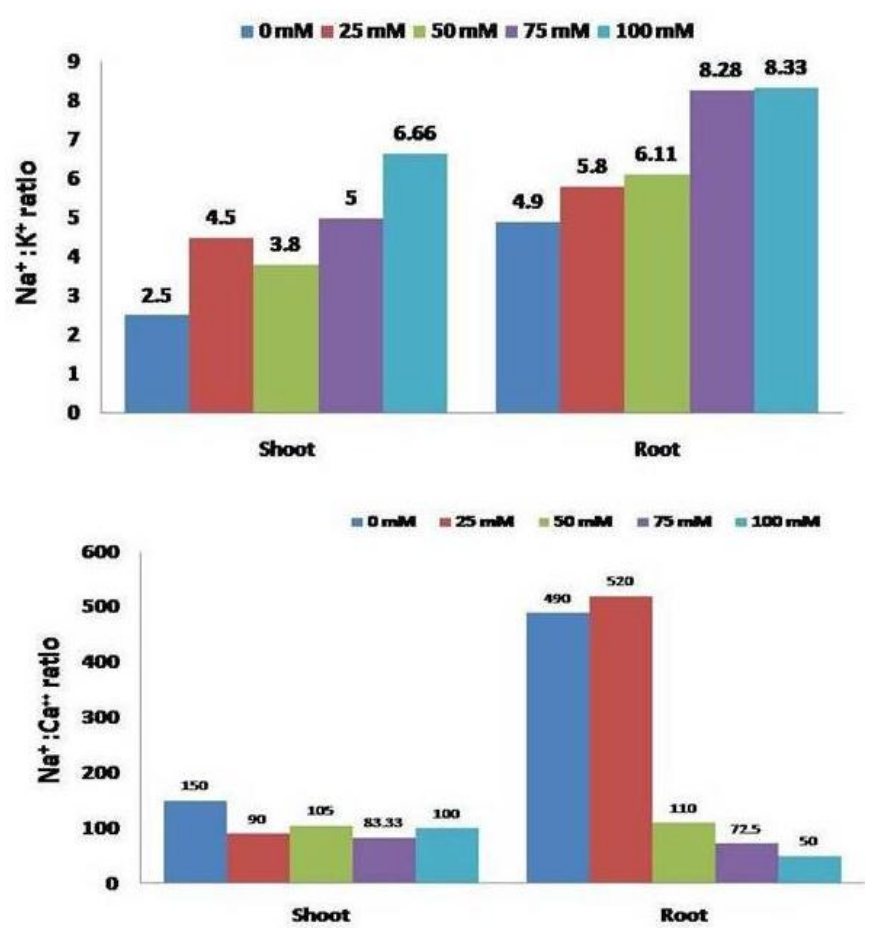

Fig. 1E:

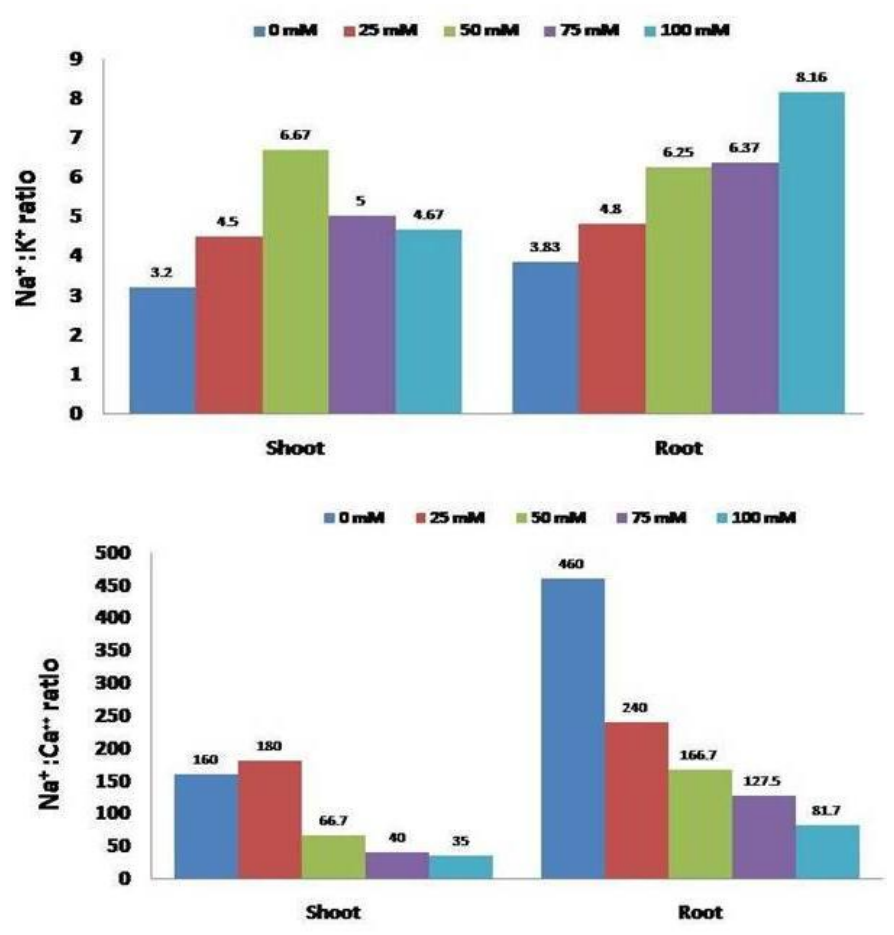

Fig. 1G:

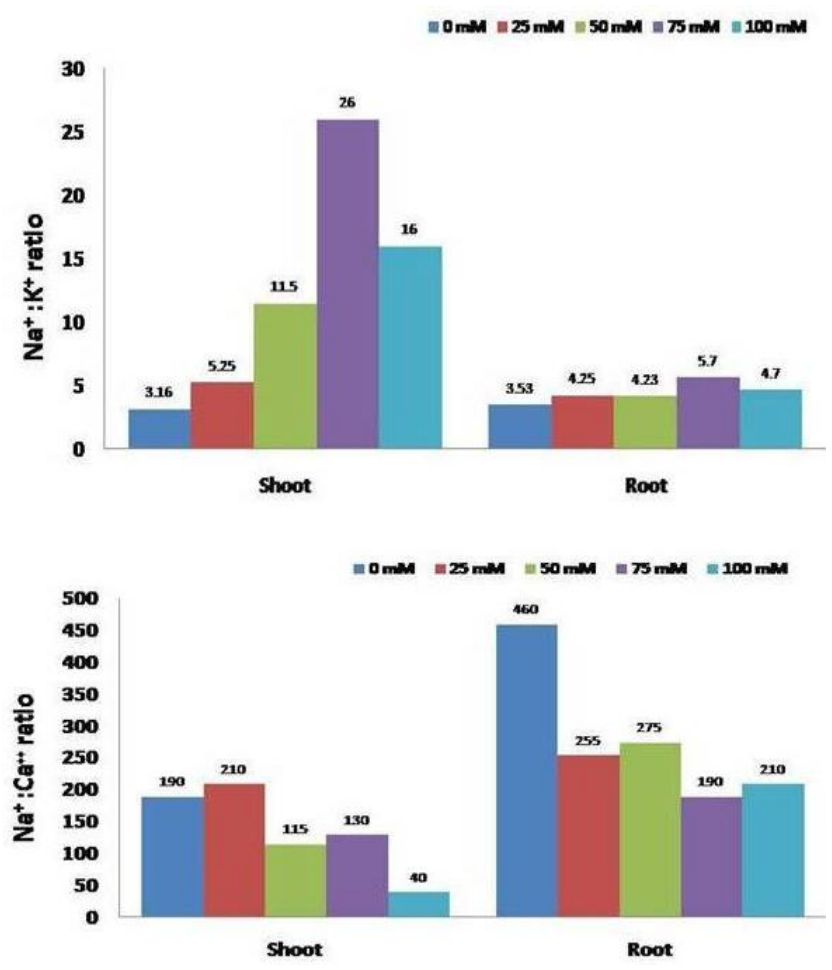

Fig. 1F:
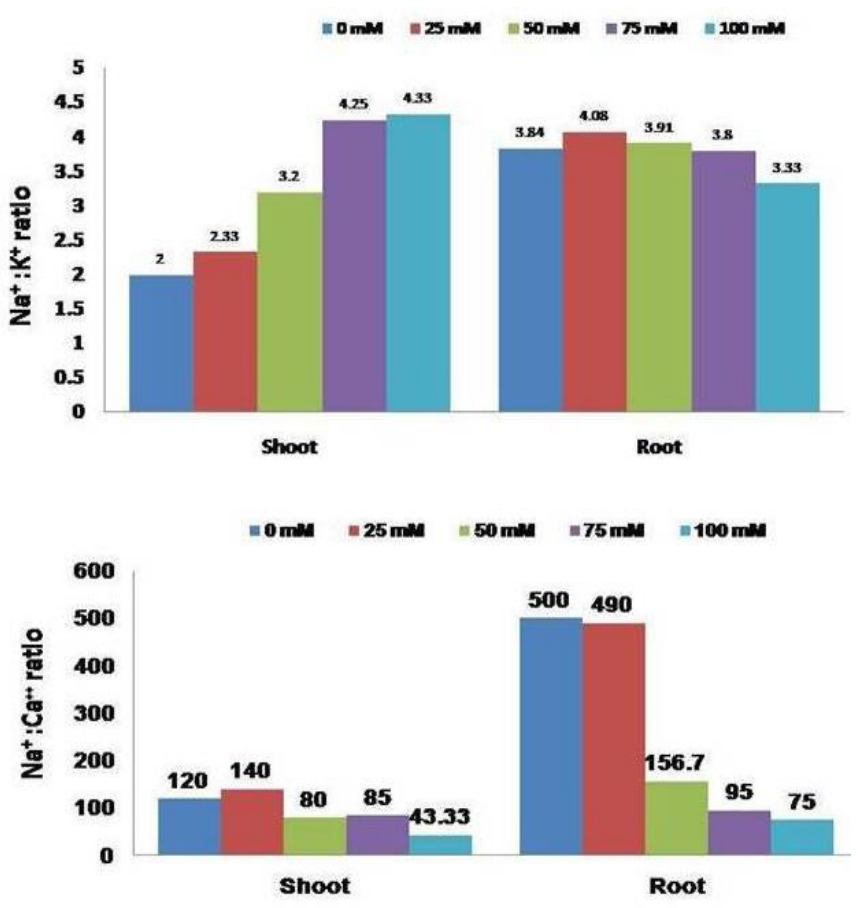

Fig. 1H: 

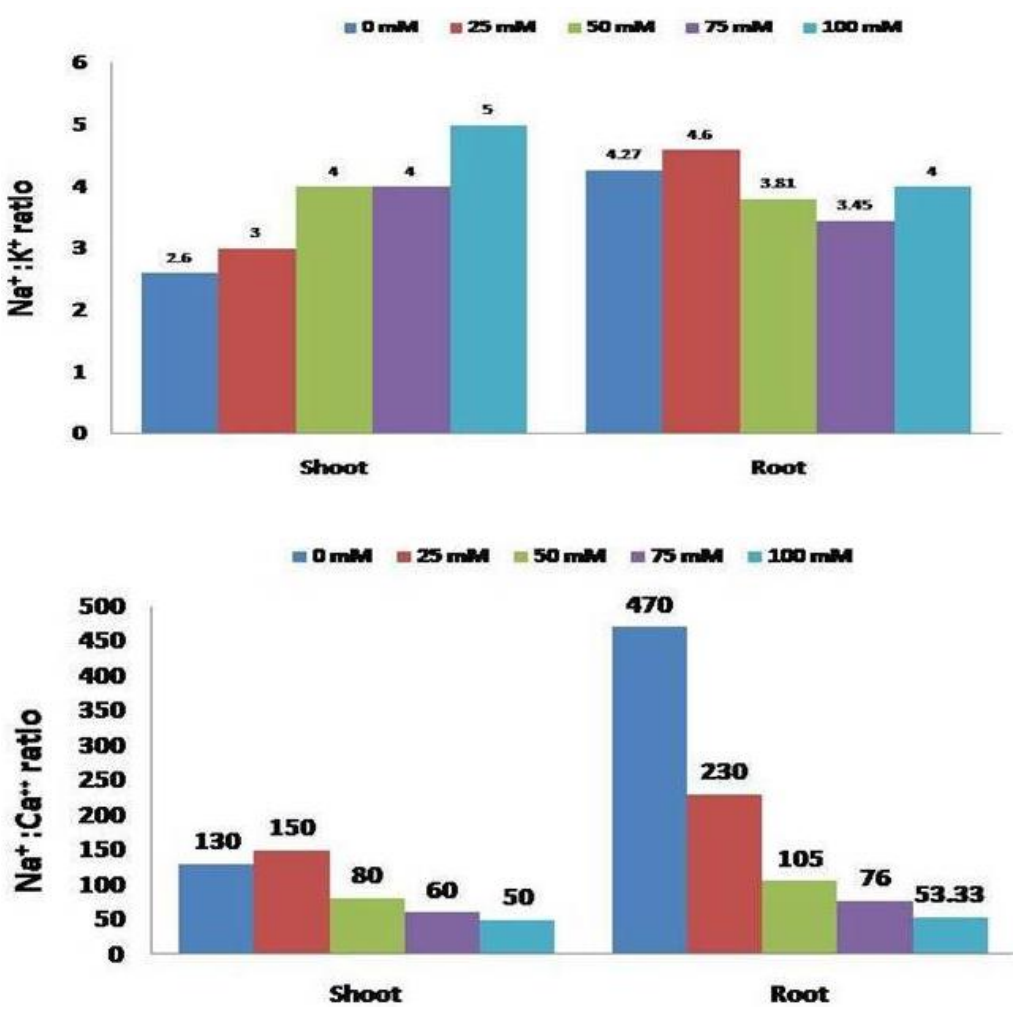

Fig. 1I:
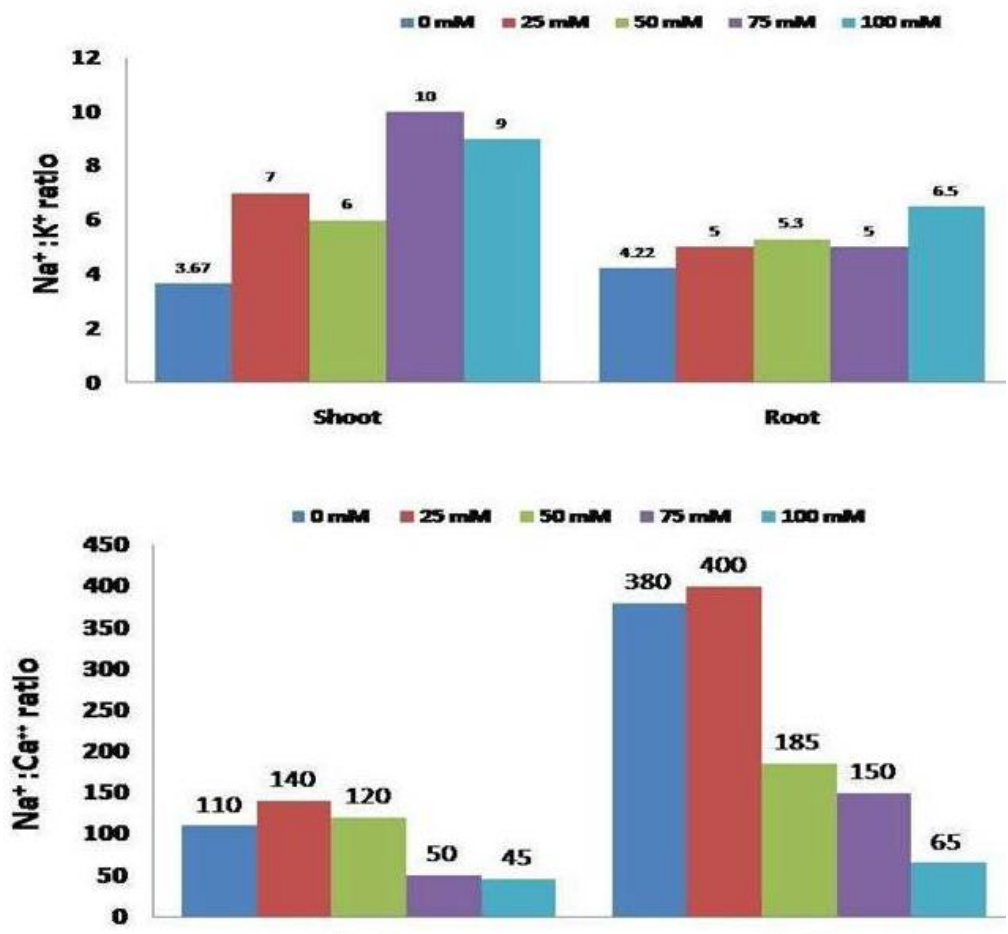

Fig. 1J:

Shoot

Root

Fig 1: Ion ratios in different genotypes of Sesamum after 15 days of application with different concentrations of NaCl. A: Kanaka, B: Parchi, C: KM-13, D: SI1926, E: S-0140, F: ENT-78-301, G: IS-607-1-84, H:SI-1025, I: SI-205, J: SI-2138-2. 
The present study showed a significant observation on $\mathrm{Na}^{+}$content in shoot and root. The tolerant genotypes maintained higher $\mathrm{K}^{+} / \mathrm{Na}^{+}$and $\mathrm{Ca}^{2+} / \mathrm{Na}^{+}$ratios which indicate of salt tolerance. Salinity also has a great impact on the nutritional status of the plant. Nutrient regulation was a vital process which was very closely linked with the salt tolerance potential. Our results indicate that the salt stress elevates the $\mathrm{Na}^{+}$ion content in shoots and roots while suppresses the content of cations $\mathrm{K}^{+}$and $\mathrm{Ca}^{+}$[35]. Both $\mathrm{K}^{+}$ and $\mathrm{Ca}^{2+}$ were key ions necessary for various physiological mechanisms under saline conditions. Khayat et al [36] reported that the salt tolerance potential was highly associated with the concentrations of inorganic osmolytes $\left(\mathrm{Na}^{+}, \mathrm{K}^{+}, \mathrm{Ca}{ }^{2+}\right)$ which can be used as screening tools for salinity tolerance. The genotypes showed higher $\mathrm{Na}^{+}$and $\mathrm{Cl}^{-}$content with increasing $\mathrm{NaCl}$ concentrations, it indicate that the genotypes may have used the ions $\left(\mathrm{Na}^{+}\right.$and $\left.\mathrm{Cl}^{-}\right)$to adjust its osmotic potential [37]. The growth of low and medium tolerant genotypes were reduced at higher $\mathrm{NaCl}$ levels may be partly due to excessive toxic ions in the cytoplasm and losing high energy through the accumulation of these ions in the vacuole. Marcum et al [38] reported that the high $\mathrm{Na}^{+} / \mathrm{K}^{+}$ratio can disturb various enzymatic processes in the cytoplasm. Salt tolerant plants respond to elevated $\mathrm{Na}^{+}$content by maintaining low cytosolic $\mathrm{Na}^{+}$concentrations with high cytosolic $\mathrm{K}^{+} / \mathrm{Na}^{+}$ratios through the extrusion or intracellular compartmentalization [39].

There was a significant difference in enzymes [Superoxide dismutase (SOD), Peroxidase (POX) and Glutathione reductase $(\mathrm{GSH})]$ activities in plants grown in different $\mathrm{NaCl}$ treatment (Tables $6-8$ ). The genotypes 'SI-1926' and 'S-0140' exhibited high activity of SOD as compared to other genotypes (Table 6).

Table 6: Superoxide dismutase (SOD) activity (U/mg protein) of ten genotypes of Sesamum indicum L. grown in soil with application of different concentrations of $\mathrm{NaCl}$.

\begin{tabular}{|c|c|c|c|c|}
\hline \multirow{2}{*}{ Genotypes } & \multirow{2}{*}{$\begin{array}{c}\mathrm{NaCl} \\
\text { concentration } \\
(\mathbf{m M})\end{array}$} & \multicolumn{3}{|c|}{$\begin{array}{c}\text { Superoxide dismutase (U/mg protein) } \\
(\text { Mean } \pm \text { SE })+\end{array}$} \\
\hline & & $\begin{array}{l}15 \text { days of } \\
\text { treatment }\end{array}$ & $\begin{array}{l}30 \text { days of } \\
\text { treatment }\end{array}$ & $\begin{array}{l}45 \text { days of } \\
\text { treatment }\end{array}$ \\
\hline \multirow[t]{5}{*}{ SI-2138-2 } & 0 & $65.0 \pm 1.2 \mathrm{i}$ & $88.3 \pm 1.4 \mathrm{~m}$ & $52.6 \pm 1.4 \mathrm{f}$ \\
\hline & 25 & $85.0 \pm 2.8 \mathrm{~m}$ & $50.2 \pm 1.5 \mathrm{e}$ & $24.4 \pm 1.2 \mathrm{~b}$ \\
\hline & 50 & $86.0 \pm 2.5 \mathrm{~m}$ & $35.4 \pm 1.2 \mathrm{c}$ & $*$ \\
\hline & 75 & $88.3 \pm 2.6 \mathrm{~m}$ & $25.0 \pm 1.6 \mathrm{~b}$ & $*$ \\
\hline & 100 & $106.6 \pm 3.4 p$ & $18.3 \pm 0.8 \mathrm{a}$ & $*$ \\
\hline \multirow[t]{5}{*}{ S-0140 } & 0 & $83.3 \pm 1.8 \mathrm{~m}$ & $91.6 \pm 1.5 \mathrm{~m}$ & $51.4 \pm 1.6 \mathrm{f}$ \\
\hline & 25 & $90.6 \pm 2.1 \mathrm{n}$ & $52.2 \pm 1.8 \mathrm{e}$ & $28.5 \pm 1.3 \mathrm{c}$ \\
\hline & 50 & $93.6 \pm 2.5 \mathrm{n}$ & $58.6 \pm 1.6 \mathrm{~g}$ & * \\
\hline & 75 & $95.0 \pm 2.0 \mathrm{o}$ & $66.7 \pm 1.4 \mathrm{~h}$ & $*$ \\
\hline & 100 & $99.3 \pm 2.4 \mathrm{p}$ & $58.3 \pm 1.3 \mathrm{~g}$ & \\
\hline \multirow[t]{5}{*}{ Prachi } & 0 & $58.3 \pm 1.8 \mathrm{~h}$ & $64.6 \pm 1.5 \mathrm{~h}$ & $65.0 \pm 2.6 \mathrm{i}$ \\
\hline & 25 & $66.6 \pm 2.5 \mathrm{i}$ & $52.4 \pm 1.8 \mathrm{e}$ & $25.0 \pm 1.2 \mathrm{~b}$ \\
\hline & 50 & $75.0 \pm 2.7 \mathrm{k}$ & $56.0 \pm 1.4 \mathrm{f}$ & $*$ \\
\hline & 75 & $58.3 \pm 1.9 \mathrm{~h}$ & $72.7 \pm 1.9 \mathrm{i}$ & $*$ \\
\hline & 100 & $79.3 \pm 2.51$ & $75.5 \pm 1.3 \mathrm{j}$ & $*$ \\
\hline \multirow[t]{3}{*}{ Kanaka } & 0 & $25.0 \pm 1.9 \mathrm{~b}$ & $58.3 \pm 1.4 \mathrm{~g}$ & $58.3 \pm 1.5 \mathrm{~h}$ \\
\hline & 25 & $38.3 \pm 3.7 \mathrm{~d}$ & $334.6 \pm 1.6 \mathrm{c}$ & $22.3 \pm 1.8 \mathrm{a}$ \\
\hline & 50 & $66.6 \pm 2.6 \mathrm{i}$ & $36.7 \pm 1.1 \mathrm{c}$ & $*$ \\
\hline
\end{tabular}

\begin{tabular}{|c|c|c|c|c|}
\hline & 75 & $58.3 \pm 3.2 \mathrm{~h}$ & $35.3 \pm 1.2 \mathrm{c}$ & $*$ \\
\hline & 100 & $69.3 \pm 3.4 \mathrm{j}$ & $16.3 \pm 1.2 \mathrm{a}$ & * \\
\hline \multirow[t]{5}{*}{ SI-1025 } & 0 & $25.0 \pm 1.8 \mathrm{~b}$ & $58.3 \pm 1.4 \mathrm{~g}$ & $33.3 \pm 1.2 \mathrm{~d}$ \\
\hline & 25 & $28.3 \pm 1.2 \mathrm{~b}$ & $68.3 \pm 1.7 \mathrm{i}$ & $41.6 \pm 1.6 \mathrm{e}$ \\
\hline & 50 & $33.3 \pm 1.4 \mathrm{c}$ & $62.7 \pm 1.5 \mathrm{~g}$ & $*$ \\
\hline & 75 & $51.0 \pm 1.5 \mathrm{f}$ & $34.3 \pm 1.2 \mathrm{c}$ & $*$ \\
\hline & 100 & $55.0 \pm 2.8 \mathrm{~g}$ & $17.8 \pm 1.4 \mathrm{a}$ & $*$ \\
\hline \multirow[t]{5}{*}{ SI-205 } & 0 & $66.6 \pm 2.5 \mathrm{i}$ & $88.4 \pm 1.6 \mathrm{~m}$ & $38.3 \pm 1.8 \mathrm{e}$ \\
\hline & 25 & $73.3 \pm 2.9 \mathrm{k}$ & $54.6 \pm 1.4 \mathrm{f}$ & $66.6 \pm 2.2 \mathrm{j}$ \\
\hline & 50 & $81.6 \pm 2.71$ & $41.6 \pm 1.7 \mathrm{~d}$ & * \\
\hline & 75 & $58.3 \pm 2.6 \mathrm{~h}$ & $42.4 \pm 1.4 \mathrm{~d}$ & $*$ \\
\hline & 100 & $25.6 \pm 1.2 \mathrm{~b}$ & $25.2 \pm 1.2 \mathrm{~b}$ & $*$ \\
\hline \multirow[t]{5}{*}{ KM-13 } & 0 & $30.6 \pm 1.8 \mathrm{c}$ & $51.6 \pm 0.6 \mathrm{e}$ & $28.7 \pm 2.7 \mathrm{c}$ \\
\hline & 25 & $26.7 \pm 1.5 \mathrm{~b}$ & $36.3 \pm 1.8 \mathrm{c}$ & $51.4 \pm 2.3 \mathrm{f}$ \\
\hline & 50 & $25.0 \pm 1.6 \mathrm{~b}$ & $62.4 \pm 1.2 \mathrm{~g}$ & * \\
\hline & 75 & $48.3 \pm 1.7 \mathrm{f}$ & $25.0 \pm 0.9 \mathrm{~b}$ & * \\
\hline & 100 & $58.4 \pm 2.6 \mathrm{~h}$ & $19.6 \pm 1.0 \mathrm{a}$ & $*$ \\
\hline \multirow{5}{*}{$\begin{array}{l}\text { IS-607-1- } \\
84\end{array}$} & 0 & $46.7 \pm 2.4 \mathrm{e}$ & $68.2 \pm 1.7 \mathrm{i}$ & $26.6 \pm 1.4 \mathrm{~b}$ \\
\hline & 25 & $55.0 \pm 1.3 \mathrm{~g}$ & $53.2 \pm 1.0 \mathrm{f}$ & $41.7 \pm 1.5 \mathrm{e}$ \\
\hline & 50 & $75.6 \pm 2.4 \mathrm{k}$ & $38.3 \pm 1.6 \mathrm{~d}$ & $*$ \\
\hline & 75 & $38.3 \pm 1.7 \mathrm{~d}$ & $28.4 \pm 1.1 \mathrm{~b}$ & $*$ \\
\hline & 100 & $25.0 \pm 1.1 \mathrm{~b}$ & $18.3 \pm 0.9 \mathrm{a}$ & * \\
\hline \multirow[t]{5}{*}{ SI-1926 } & 0 & $91.6 \pm 1.5 \mathrm{n}$ & $28.8 \pm 0.6 \mathrm{~b}$ & $32.4 \pm 2.7 \mathrm{~d}$ \\
\hline & 25 & $66.6 \pm 2.7 \mathrm{i}$ & $36.7 \pm 1.1 \mathrm{c}$ & $56.0 \pm 2.8 \mathrm{~g}$ \\
\hline & 50 & $41.6 \pm 1.4 \mathrm{~d}$ & $41.7 \pm 1.6 \mathrm{~d}$ & * \\
\hline & 75 & $28.6 \pm 1.6 \mathrm{c}$ & $67.5 \pm 1.2 \mathrm{~h}$ & * \\
\hline & 100 & $20.7 \pm 1.5 \mathrm{a}$ & $68.3 \pm 2.1 \mathrm{i}$ & * \\
\hline \multirow{5}{*}{$\begin{array}{l}\text { ENT-78- } \\
301\end{array}$} & 0 & $21.3 \pm 1.2 \mathrm{a}$ & $83.3 \pm 1.61$ & $52.4 \pm 2.8 \mathrm{f}$ \\
\hline & 25 & $26.8 \pm 1.5 \mathrm{~b}$ & $58.3 \pm 1.5 \mathrm{~g}$ & $22.3 \pm 1.6 \mathrm{a}$ \\
\hline & 50 & $30.7 \pm 1.7 \mathrm{c}$ & $48.3 \pm 1.3 \mathrm{e}$ & * \\
\hline & 75 & $38.3 \pm 1.2 \mathrm{~d}$ & $34.3 \pm 1.1 \mathrm{c}$ & * \\
\hline & 100 & $58.3 \pm 1.8 \mathrm{~h}$ & $23.6 \pm 0.7 \mathrm{~b}$ & * \\
\hline
\end{tabular}

*Plant did not survived, +10 replicates / treatment; repeated twice. Means having the same letter in a column were not significantly different by Duncan's multiple range test $P<0.05$ level.

The maximum activity of SOD was recorded in 'SI2138-2' (106.66\% of inhibition) at $100 \mathrm{mM} \mathrm{NaCl}$ after 15 days of application. POX activity increases with increase of $\mathrm{NaCl}$ concentration in all genotypes grown under 15 \& 30 days (Table 7).

Table 7: Peroxidase (POX) activity ( $\mu \mathrm{mol} / \mathrm{min} / \mathrm{mg}$ protein) of ten genotypes of Sesamum indicum L. grown in soil with application of different concentrations of $\mathrm{NaCl}$.

\begin{tabular}{|c|c|c|c|c|}
\hline \multirow{2}{*}{ Genotypes } & \multirow{2}{*}{$\begin{array}{c}\mathrm{NaCl} \\
\text { concentrat } \\
\text { ion }(\mathrm{mM})\end{array}$} & \multicolumn{3}{|c|}{$\begin{array}{c}\text { Peroxidase }(\mu \mathrm{mol} / \mathrm{min} / \mathrm{mg} \text { protein }) \\
(\text { Mean } \pm \mathrm{SE})+\end{array}$} \\
\hline & & $\begin{array}{l}15 \text { days of } \\
\text { treatment }\end{array}$ & $\begin{array}{l}30 \text { days of } \\
\text { treatment }\end{array}$ & $\begin{array}{l}45 \text { days of } \\
\text { treatment }\end{array}$ \\
\hline \multirow[t]{5}{*}{ SI-2138-2 } & 0 & $0.45 \pm 0.08 \mathrm{c}$ & $1.21 \pm 0.4 \mathrm{~b}$ & $2.14 \pm 0.6 \mathrm{~b}$ \\
\hline & 25 & $0.39 \pm 0.05 \mathrm{~b}$ & $1.88 \pm 0.6 \mathrm{~d}$ & $3.29 \pm 0.4 \mathrm{c}$ \\
\hline & 50 & $0.44 \pm 0.02 \mathrm{~b}$ & $2.82 \pm 0.4 \mathrm{f}$ & $*$ \\
\hline & 75 & $0.49 \pm 0.04 \mathrm{c}$ & $2.87 \pm 0.6 \mathrm{f}$ & $*$ \\
\hline & 100 & $0.91 \pm 0.05 \mathrm{~g}$ & $2.92 \pm 0.7 \mathrm{f}$ & $*$ \\
\hline \multirow[t]{5}{*}{ S-0140 } & 0 & $0.56 \pm 0.08 \mathrm{c}$ & $0.79 \pm 0.04 \mathrm{a}$ & $2.36 \pm 0.3 b$ \\
\hline & 25 & $0.30 \pm 0.03 \mathrm{a}$ & $0.72 \pm 0.02 \mathrm{a}$ & $1.61 \pm 0.2 \mathrm{a}$ \\
\hline & 50 & $0.47 \pm 0.06 \mathrm{c}$ & $0.83 \pm 0.09 \mathrm{a}$ & $*$ \\
\hline & 75 & $0.83 \pm 0.04 \mathrm{f}$ & $0.99 \pm 0.06 \mathrm{a}$ & $*$ \\
\hline & 100 & $1.05 \pm 0.4 \mathrm{~h}$ & $1.78 \pm 0.4 \mathrm{~d}$ & $*$ \\
\hline \multirow[t]{5}{*}{ Prachi } & 0 & $0.35 \pm 0.08 \mathrm{a}$ & $0.81 \pm 0.06 \mathrm{a}$ & $1.98 \pm 0.4 \mathrm{~b}$ \\
\hline & 25 & $0.38 \pm 0.02 \mathrm{~b}$ & $0.95 \pm 0.03 \mathrm{a}$ & $2.04 \pm 0.3 \mathrm{~b}$ \\
\hline & 50 & $0.48 \pm 0.04 \mathrm{c}$ & $0.99 \pm 0.06 \mathrm{a}$ & $*$ \\
\hline & 75 & $0.73 \pm 0.09 \mathrm{e}$ & $1.04 \pm 0.5 \mathrm{~b}$ & $*$ \\
\hline & 100 & $0.85 \pm 0.05 \mathrm{f}$ & $1.86 \pm 0.7 \mathrm{~d}$ & $*$ \\
\hline \multirow[t]{2}{*}{ Kanaka } & 0 & $0.31 \pm 0.04 \mathrm{a}$ & $1.44 \pm 0.3 \mathrm{c}$ & $3.77 \pm 0.2$ \\
\hline & 25 & $0.33 \pm 0.03 \mathrm{a}$ & $2.03 \pm 0.6 \mathrm{~d}$ & $2.24 \pm 0.8 \mathrm{~b}$ \\
\hline
\end{tabular}




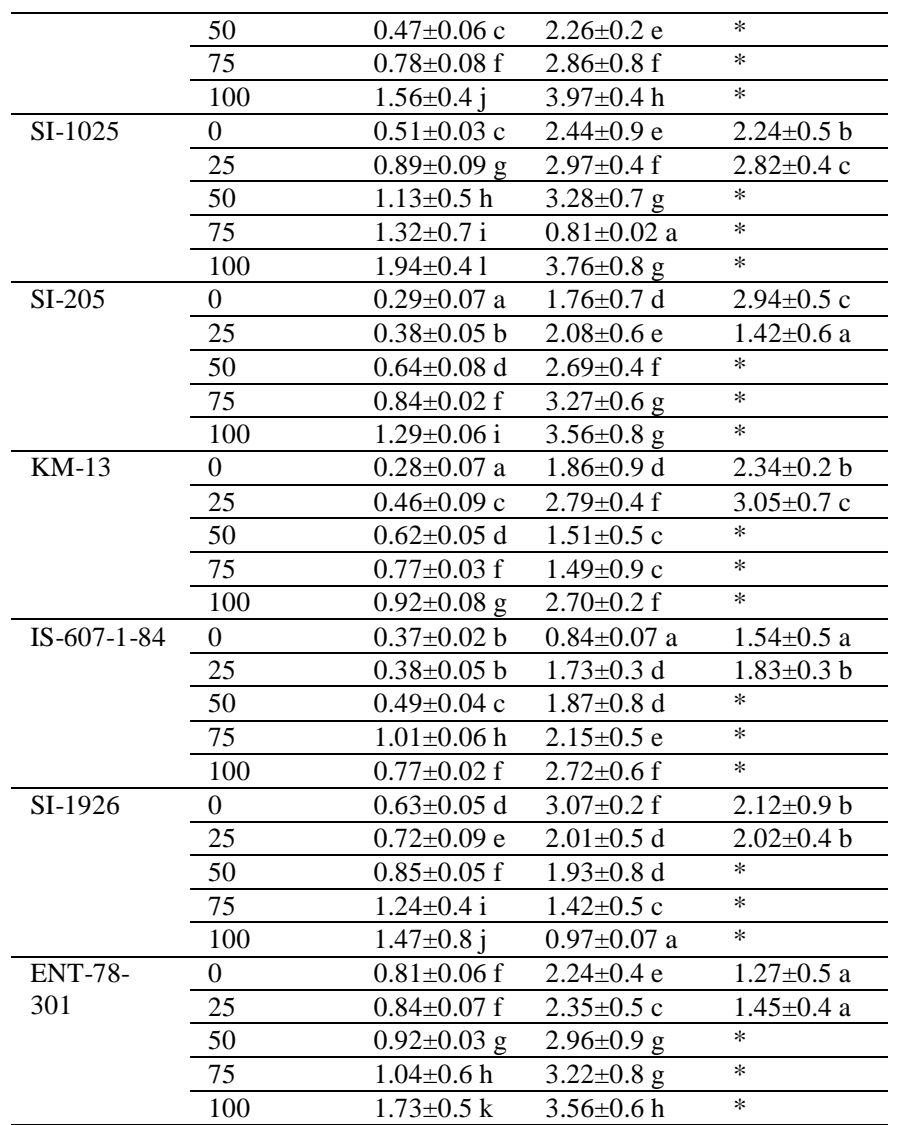

*Plant did not survive +10 replicates / treatment; repeated twice. Means having the same letter in a column were not significantly different by Duncan's multiple range test $P<0.05$ level.

Table 8: Glutathione peroxidase (PXR) activity (Unit / mg protein) of ten genotypes of Sesamum indicum L. grown in soil with application of different concentrations of $\mathrm{NaCl}$

\begin{tabular}{|c|c|c|c|c|}
\hline \multirow[b]{2}{*}{ Genotypes } & \multirow{2}{*}{$\begin{array}{c}\mathrm{NaCl} \\
\text { concent } \\
\text { ration } \\
(\mathbf{m M})\end{array}$} & \multicolumn{3}{|c|}{$\begin{array}{c}\text { Glutathione peroxidase (Unit / mg protein) } \\
(\text { Mean } \pm \text { SE })+\end{array}$} \\
\hline & & $\begin{array}{c}\text { After } 15 \text { days } \\
\text { of treatment }\end{array}$ & $\begin{array}{c}\text { After } 30 \\
\text { days of } \\
\text { treatment }\end{array}$ & $\begin{array}{c}\text { After } 45 \\
\text { days of } \\
\text { treatment }\end{array}$ \\
\hline \multirow[t]{5}{*}{ SI-2138-2 } & 0 & $0.18 \pm 0.05 \mathrm{a}$ & $0.74 \pm 0.04 \mathrm{~b}$ & $2.75 \pm 0.8 \mathrm{~b}$ \\
\hline & 25 & $0.50 \pm 0.06 \mathrm{~b}$ & $1.55 \pm 0.3 \mathrm{e}$ & $1.64 \pm 0.6 \mathrm{a}$ \\
\hline & 50 & $0.59 \pm 0.03 \mathrm{~b}$ & $4.00 \pm 0.8 \mathrm{~h}$ & * \\
\hline & 75 & $1.24 \pm 0.4 \mathrm{c}$ & $5.56 \pm 0.7 \mathrm{i}$ & $*$ \\
\hline & 100 & $0.47 \pm 0.02 \mathrm{~b}$ & $7.09 \pm 0.4 \mathrm{k}$ & $*$ \\
\hline \multirow[t]{5}{*}{ S-0140 } & 0 & $1.94 \pm 0.6 \mathrm{e}$ & $5.16 \pm 0.8 \mathrm{i}$ & $3.51 \pm 0.5 \mathrm{c}$ \\
\hline & 25 & $1.89 \pm 0.5 \mathrm{e}$ & $5.36 \pm 0.7 \mathrm{i}$ & $6.73 \pm 0.8 \mathrm{e}$ \\
\hline & 50 & $1.52 \pm 0.7 \mathrm{~d}$ & $6.53 \pm 0.9 \mathrm{j}$ & $*$ \\
\hline & 75 & $0.70 \pm 0.06 \mathrm{~b}, \mathrm{c}$ & $5.01 \pm 0.6 \mathrm{i}$ & $*$ \\
\hline & 100 & $0.57 \pm 0.08 \mathrm{~b}$ & $1.07 \pm 0.4 \mathrm{~d}$ & $*$ \\
\hline \multirow[t]{5}{*}{ Prachi } & 0 & $0.32 \pm 0.09 \mathrm{a}, \mathrm{b}$ & $1.47 \pm 0.7 \mathrm{e}$ & $4.00 \pm 0.2 \mathrm{c}$ \\
\hline & 25 & $0.52 \pm 0.06 \mathrm{c}$ & $1.21 \pm 0.4 \mathrm{~d}$ & $5.16 \pm 0.7 \mathrm{~d}$ \\
\hline & 50 & $1.89 \pm 0.7 \mathrm{e}$ & $1.36 \pm 0.3 \mathrm{~d}, \mathrm{e}$ & $*$ \\
\hline & 75 & $0.70 \pm 0.04 \mathrm{~b}, \mathrm{c}$ & $0.85 \pm 0.08 \mathrm{c}$ & $*$ \\
\hline & 100 & $0.47 \pm 0.06 \mathrm{~b}$ & $0.63 \pm 0.07 \mathrm{~b}$ & $*$ \\
\hline \multirow[t]{5}{*}{ Kanaka } & 0 & $1.89 \pm 0.5 \mathrm{e}$ & $5.20 \pm 0.6 \mathrm{i}$ & $10.00 \pm 0.8 \mathrm{~g}$ \\
\hline & 25 & $0.32 \pm 0.08 \mathrm{a}$ & $6.74 \pm 0.9 \mathrm{j}$ & $10.53 \pm 1.2 \mathrm{~g}$ \\
\hline & 50 & $0.57 \pm 0.09 \mathrm{~b}$ & $8.91 \pm 0.41$ & $*$ \\
\hline & 75 & $0.79 \pm 0.05 \mathrm{~b}, \mathrm{c}$ & $4.10 \pm 0.8 \mathrm{~h}$ & $*$ \\
\hline & 100 & $0.52 \pm 0.07 \mathrm{~b}$ & $1.34 \pm 0.3 \mathrm{~d}, \mathrm{e}$ & $*$ \\
\hline \multirow[t]{2}{*}{ SI-1025 } & 0 & $0.49 \pm 0.04 \mathrm{~b}$ & $0.74 \pm 0.07 \mathrm{~b}$ & $5.76 \pm 0.5 \mathrm{~d}$ \\
\hline & 25 & $0.73 \pm 0.03 \mathrm{~b}, \mathrm{c}$ & $8.07 \pm 0.41$ & $8.07 \pm 0.7 \mathrm{f}$ \\
\hline
\end{tabular}

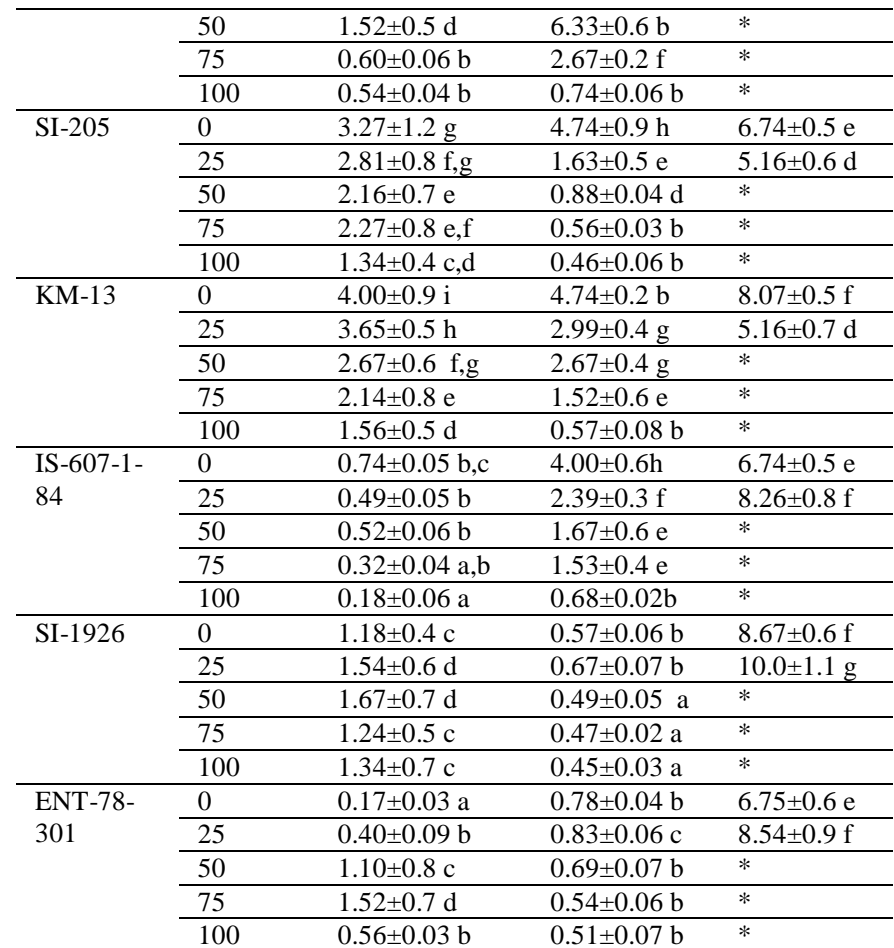

*Plant did not survived, +10 replicates / treatment; repeated twice. Means having the same letter in a column were not significantly different by Duncan's multiple range test $P<0.05$ level.

The genotype 'SI-1025' showed highest activity $(1.941 \mu \mathrm{mol} / \mathrm{min} / \mathrm{mg}$ protein) at $100 \mathrm{mM}$ after15 days of treatment. The GPX activity decreased with increase of $\mathrm{NaCl}$ application. SOD is one of the most important antioxidant enzymes and is the first line of cellular defense against the oxidative stress [25, 32]. SOD plays an important role in modulating the relative amount of $\mathrm{O} 2 \cdot-$ and $\mathrm{H}_{2} \mathrm{O}_{2}$ in plants and hence, performs a key role in the defense mechanism against ROS toxicity [22].

In the present study, the higher SOD activity is found in the genotype 'SI-2138-2' (106.66 Unit per mg protein) grown at $100 \mathrm{mM} \mathrm{NaCl}$ for 15 days. It was also observed that the activity declined after 30 days of treatment.

The observed depression in SOD activity could be regarded as the lack of an ability to scavenge $\mathrm{O} 2 \bullet$ - radicals in prolonged stress which could lead to cellular damage and suppression of plant growth.

Many studies have found positive correlations between salt stress tolerance and the level of SOD activity in different plant species $[33,40]$.

The major function of GSH in plants appears to be the scavenging of phospholipid hydroperoxides and thereby the protection of cell membranes from peroxidative damage $[6,41$, 42]. The expression of many GPX is enhanced in response to abiotic and biotic stresses, including salinity, heavy metal toxicity and infection with bacterial or viral pathogens. This study will help in Sesamum improvement program. 


\section{ACKNOWLEDGEMENTS}

The authors wish to acknowledge to AICRP Sesamum, OUAT, Bhubaneswar for providing seed materials for experiment.

\section{Financial support and sponsorship: Nil.}

Conflict of Interests: There are no conflicts of interest.

\section{REFERENCES}

1. Ashri A. In J Janick (Ed.), Plant breeding reviews, 2010, Vol. 16, Oxford, Wiley

2. Bedigian D, Harlan JR. Evidence for cultivation of sesame in the ancient world. Economic Botany. 1986; 40: 137-154.

3. FAOSTAT. Food and Agriculture organization of the United Nations. 2012, http://faostat.fao.

4. Morris JB. Food, industrial, nutraceutical, and pharmaceutical uses of sesame genetic resources. In: Janick, J., Whipkey, A. (Eds.), Trends in New Crops and New Uses. 2002, ASHS Press, Alexandria, VA, pp 153 156.

5. FAO (2000) The State of Food and Agriculture, 2000 (www.fao.org).

6. Parida AK, Das AB. Salt tolerance and salinity effects on plants. Ecotoxicology \& Environ.2005; 60: 324-349.

7. Evans LT. Feeding the ten billion. Cambridge University Press, 1983 , pp.247.

8. Li G, Wan S, Zhou J, Yang Z, Qin P. Leaf chlorophyll fluorescence, hyperspectral reflectance, pigments content, malondialdehyde and proline accumulation responses of castor bean (Ricinus communis 1.) seedlings to salt stress levels. Indust. Crop. Product. 2010; 31: 13-19.

9. Azevedo Neto AD, Prisco JT, EnéasFilho J, Abreu CEBD, Gomes Filho E. Effect of salt stress on antioxidative enzymes and lipid peroxidation in leaves and roots of salt tolerant and salt-sensitive maize genotypes. Environ. Experimental Bot.2006; 56: 87-94.

10. Amirjani MR. Effects of salinity stress on growth, mineral composition, proline content, antioxidant enzymes of soybean. Am. J. Physiol. 2010; 5: 350-360.

11. Leshem Y, Seri L, Levine A. Induction of Phosphatidylinositol 3-kinase mediated endocytosis by Salt Stress Leads to Intracellular Production of Reactive Oxygen Species and Salt Tolerance. Plant Jour. 2007; 51:185197.

12. Abogadallah GM. Antioxidative Defense under Salt Stress. Plant Signal. Behav., 2010; 5: 369-374

13. Hoagland DR, Arnon DI. The water-culture method of growing plants without soil. Calif. Agr. Expt. Sta. Circ. 1950, p.347.

14. Bates LS, Waldren RP, Teare ID. Rapid determination of free proline for water-stress studies. Plant Soil. 1973; 39: 205-207.

15. Giannopolitis CN, Ries SK. Superoxide dismutases. I. Occurrence in Higher Plants. Plant Physiol.1977; 59: 309-314

16. Tomiyama K. and Stahmann MA. Alteration of oxidative enzymes in potato tuber tissue by infection with Phytophthora infestans. Plant Physiol.1964; 39: 483-490.

17. Wendel A. Glutathione Peroxidases. In: Enzymatic basis of detoxification, Jakoby WB. (Ed.). Academic Press, New York. 1980; pp. 333-353.

18. Ruiz JM., Blasco B., Rivero RM, Romero L. Nicotine-free and salt tolerant tobacco plants obtained by grafting to salinity-resistant rootstocks of tomato. Physiol. Plant. 2005; 124: 465-475.

19. Munns R, Tester M. Mechanisms of Salinity Tolerance. Ann. Rev. Plant Biol. 2008; 59: 651-681.

20. Azizpour K., Shakiba MR, Sima KK, Alyari H, Mogaddam M, Esfandiari E, Pessarakli. M. Physiological Response of Spring Durum Wheat Genotypes to Salinity. Jour. Plant Nut. 2010; 33:859-873.

21. Bazrafshan AH, Ehsanzadeh P. Growth, Photosynthesis and Ion balance of Sesame (Sesamum indicum L.) genotypes in response to $\mathrm{NaCl}$ Concentration in hydroponic Solutions. Photosynthetica. 2014; 52: $134-$ 147.

22. Meloni DA, Oliva MA, Martinez CA, Cambraia J. Photosynthesis and Activity of superoxide dismutase, peroxidase and glutathione reductase in Cotton under Salt Stress. Environ. Exp. Bot. 2003; 49:69-76.

23. Nasir Khan M, Siddiqui H, Masroor M, Khan A, Naeem M Salinity induced changes in growth, enzyme activities, photosynthesis, proline accumulation and yield in linseed genotypes. World Jour. Agric. Sci.2007; 3: 685-695.

24. Kaymakanova M, Stoeva N. Physiological reaction of bean plants (Phaseolus vulgaris L.) to salt stress. Gen. Appl. Plant Physiol. 2008; 34 : 177-188.

25. Tuna AL, Kaya C, Dikilitas M, Higgs D. The combined effects of gibberellic acid and salinity on some antioxidant enzyme activities, plan growth parameters and nutritional status in maize plants. Environ. Exp. Bot. 2008; 62:1-9.

26. Ehsanzadeh P, Sabagh Nekoonam M, Nouri Azhar J, Pourhadian H, Shaydaee F.

27. Growth, chlorophyll, and cation concentration of tetraploid wheat on a solution high in sodium chloride Salt: Hulled Versus Free-threshing Genotypes. Jour. Plant Nut. 2009; 32: 58-70.

28. Maksimović I, Putnik-Delić M, Gani I, Marić J, Ilin Ž. Growth, ion composition, and stomatal conductance of Peas Exposed to Salinity. Central Europe Jour. Biol. 2010; 5: 682-691.

29. Farissi M, Faghir M, Bargaz A, Bouizgaren A, Makoudi B, Sentenac $\mathrm{H}$, Ghoulam C. Growth, nutrients concentration, and enzymes Involved in plants nutrition Alfalfa populations under saline conditions. Jour. Agr. Sci. Tech. 2014; 16: 301-314.

30. Kafi M, Shariat Jafari MH, Moayedi A. The Sensitivity of Grain Sorghum (Sorghum bicolor L.) Developmental Stages to Salinity Stress: An Integrated Approach. Jour. Agr. Sci. Tech. 2013; 15: 723-736.

31. Flowers TJ, Gaur PM, Gowda CLL, Samineni KS, Siddique KHM, Turner NC, Vadez V, Varshney RK, Colmer TD. Salt sensitivity in chickpea. Plant Cell. Environ. 2010; 33: 490-509.

32. Ashraf M, Harris PJC. Potential Biochemical Indicators of Salinity Tolerance in Plants. Plant Sci. 2004; 166: 3-16.

33. Demiral T, Türkan I. Comparative lipid peroxidation, antioxidant defense systems and proline content in roots of two rice cultivars differing in Salt Tolerance. Environ. Exp. Bot. 2005; 53: 247-257.

34. Koca H, Bor M, Özdemir F, Türkan I. The Effect of salt stress on lipid peroxidation, antioxidative enzymes and proline content of sesame cultivars. Environ. Exp. Bot. 2007; 60: 344-351.

35. Zushi K, Matsuzoe N. Postharvest changes in sugar, organic acid, glutamic acid and antioxidant contents in tomato fruit grown under salinity stress. Environment Control in Biol. 2006; 44:111-117.

36. Akram M, Ashraf MY, Ahmad R, Waraich EA, Iqbal J, Mohsan M. Screening for salt tolerance in maize (Zea mays L.) hybrids at an early seedling stage. Pak. Jour. Bot. 2010; 42:141-154.

37. Khayat PN, Jamaati-e-Somarin S, Zabihi-e-Mahmoodabad R, Yari A, Khayatnezhad M, Gholamin R. Screening of salt tolerance canola cultivars using physiological markers. World Applied Soil Jour. 2010; $10 ; 817-820$

38. Khan MA, Unger IA, Showalter AM. Effects of salinity on growth, ion content and osmotic relations in Halopyrum mucronatum (L.) Stapf. Journal of Plant Nutrition. 1999; 22:191-204.

39. Marcum KB, Yensen NP, Leake JE. Genotypic variation in salinity tolerance of Distichlis spicata turf ecotypes. Aust. Jour. Expt. Agricult. 2007; 47:1506-1511.

40. Blumwald E. Sodium transport and salt tolerance in plants. Current Opinion in Cell Biol. 2000; 12:431-434

41. Bor M, Özdemir F, Türkan I. The effect of Salt Stress on lipid peroxidation and antioxidants in Leaves of sugar beet (Beta vulgaris L.) and Wild Beet (Beta maritime L.). Plant Sci.2003; 164: 77-84

42. Dionisio-Sese ML, Tobita S. Antioxidant responses of rice seedlings to salinity stress. Plant Sci. 1998; 135: 1-9.

43. Vaidyanathan H, Sivakumar P, Chakrabarty R, Thomas G. Scavenging of reactive oxygen species in $\mathrm{NaCl}$-stressed Rice (Oryza sativa L.) differential response in salt-tolerant and sensitive varieties. Plant Sci 2003; 165: 1411-1418.

\section{How to cite this article:}

Hota T, Pradhan C, Rout GR. Physiological and biochemical characterization of Sesamum germplasms tolerant to $\mathrm{NaCl}$. J App Biol Biotech. 2016; 4 (05): 014-025. doi: 10.7324/JABB.2016.40503 